\title{
Beyond the catalyst: how electrode and reactor design determine the product spectrum during electrochemical $\mathrm{CO}_{2}$ reduction
}

\author{
Jan-Bernd Vennekötter ${ }^{\mathrm{a}}$, Robert Sengpiel ${ }^{\mathrm{a}}$, Matthias Wessling ${ }^{\mathrm{a}}{ }^{\mathrm{ab}}$ \\ ${ }^{a}$ RWTH Aachen University \\ Aachener Verfahrenstechnik-Chemical Process Engineering. \\ Forckenbeckstr. 51, 52074 Aachen, Germany. \\ Email: matthias.wessling@avt.rwth-aachen.de \\ Tel: +49 24180-95470; Fax: +49 24180-92252 \\ ${ }^{b}$ DWI-Leibniz Institute for Interactive Materials \\ Forckenbeckstr. 50, 52074 Aachen, Germany
}

\begin{abstract}
As a remedy to the increasing concentration of greenhouse gases and depleting fossil resources, the electrochemical $\mathrm{CO}_{2}$ reduction closes the carbon cycle and provides an alternative carbon feedstock to the chemical and energy industry. While most contemporary research focuses on the catalyst activity, we emphasize the importance of the reactor design for an energetic efficient (EE) conversion. A design strategy for an electrochemical membrane reactor reducing $\mathrm{CO}_{2}$ to hydrogen, carbon monoxide $(\mathrm{CO})$ and ethylene $\left(\mathrm{C}_{2} \mathrm{H}_{4}\right)$ is developed. We present the stepwise development from an H-cell like setup using full-metal electrodes to a cell with gas diffusion electrodes (GDE) towards high current efficiencies (CE) at high current densities (CD). At $300 \mathrm{~mA} \mathrm{~cm}^{-2}$ a CO-CE of $56 \%$ for a $\mathrm{Ag}$ GDE and a $\mathrm{C}_{2} \mathrm{H}_{4}$-CE of 94\% for a $\mathrm{Cu}$ GDE are measured. The incorporation of the developed GDEs into a zero-gap assembly eliminates ohmic losses and maximizes EE, however the acidic environment of the ion exchange membrane inhibits $\mathrm{CO}_{2}$ reduction. As a compromise a thin liquid buffer layer between cathode and membrane is a prerequisite for a highly active conversion. We demonstrate that industrial relevant CDs with high CEs and EEs can only be achieved by moving beyond today's research form catalyst development only to an integrated reactor design, which allows to exploit the viable potential of electrochemical $\mathrm{CO}_{2}$ reduction catalysts. Keywords: $\mathrm{CO}_{2}$ reduction, reactor design, gas diffusion electrodes, $\mathrm{C} 2$
\end{abstract}




\section{Abbreviations}

Table 1: List of abbreviations

\begin{tabular}{|c|c|c|}
\hline Abbreviation & Full Name & Unit \\
\hline $\mathrm{Ag}$ & silver & {$[-]$} \\
\hline $\mathrm{C}_{2} \mathrm{H}_{4}$ & ethylene & {$[-]$} \\
\hline $\mathrm{CCM}$ & catalyst coated membrane & {$[-]$} \\
\hline $\mathrm{CD}$ & current density & {$\left[\mathrm{mA} \mathrm{cm}^{-2}\right]$} \\
\hline $\mathrm{CE}$ & current efficiency & {$[\%]$} \\
\hline CEM & cation exchange membrane & {$[-]$} \\
\hline $\mathrm{CH}_{4}$ & methane & {$[-]$} \\
\hline $\mathrm{CO}_{2}$ & carbon dioxide & [-] \\
\hline $\mathrm{CO}$ & carbon monoxide & {$[-]$} \\
\hline $\mathrm{Cu}$ & copper & {$[-]$} \\
\hline ecMR & electrochemical membrane reactor & {$[-]$} \\
\hline $\mathrm{EE}$ & energetic efficiency & {$[\%]$} \\
\hline $\mathrm{GC} / \mathrm{MS}$ & gas chromatography - mass spectrometry & {$[-]$} \\
\hline GDE & gas diffusion electrode & {$[-]$} \\
\hline GDL & gas diffusion layer & {$[-]$} \\
\hline $\mathrm{H}_{2}$ & hydrogen & {$[-]$} \\
\hline $\mathrm{HCOOH}$ & formic acid & {$[-]$} \\
\hline LSV & linear sweep voltammetry & {$[-]$} \\
\hline OER & oxygen evolution reaction & {$[-]$} \\
\hline PEM & polymer electrolyte membrane & {$[-]$} \\
\hline RHE & reversible hydrogen electrode & {$[-]$} \\
\hline RWGS & reverse water-gas shift & {$[-]$} \\
\hline $\mathrm{SG}$ & synthesis gas & {$[-]$} \\
\hline
\end{tabular}


Table 2: List of symbols

\begin{tabular}{l|l|l} 
Symbol & Full Name & Unit \\
\hline \hline$\eta_{\mathrm{CE}, \mathrm{i}}$ & current efficiency for species i & {$[\%]$} \\
$\eta_{\Omega \mathrm{s}, \mathrm{i}}$ & ohmic potential drop of solid electrode (i: cathode or anode) & {$[\mathrm{V}]$} \\
$\eta_{\Omega \mathrm{l}, \mathrm{i}}$ & ohmic potential loss in electrolyte (i: cathode or anode) & {$[\mathrm{V}]$} \\
$\eta_{\mathrm{m}}$ & ohmic potential loss over membrane & {$[\mathrm{V}]$} \\
$\eta_{\Omega, \text { total }}$ & ohmic potential drop of catholyte, anolyte and membrane & {$[\mathrm{V}]$} \\
$\eta_{\mathrm{c}, \mathrm{i}}$ & concentration overpotential (i: cathode or anode) & {$[\mathrm{V}]$} \\
$\eta_{\mathrm{rt}, \mathrm{i}}$ & reaction overpotential (i: cathode or anode) & {$[\mathrm{V}]$} \\
$\mathrm{E}_{\mathrm{cell}}$ & cell potential & {$[\mathrm{V}]$} \\
$\mathrm{E}_{\text {Onset }}$ & onset potential for electrochemical reaction & {$[\mathrm{V}]$} \\
\hline
\end{tabular}



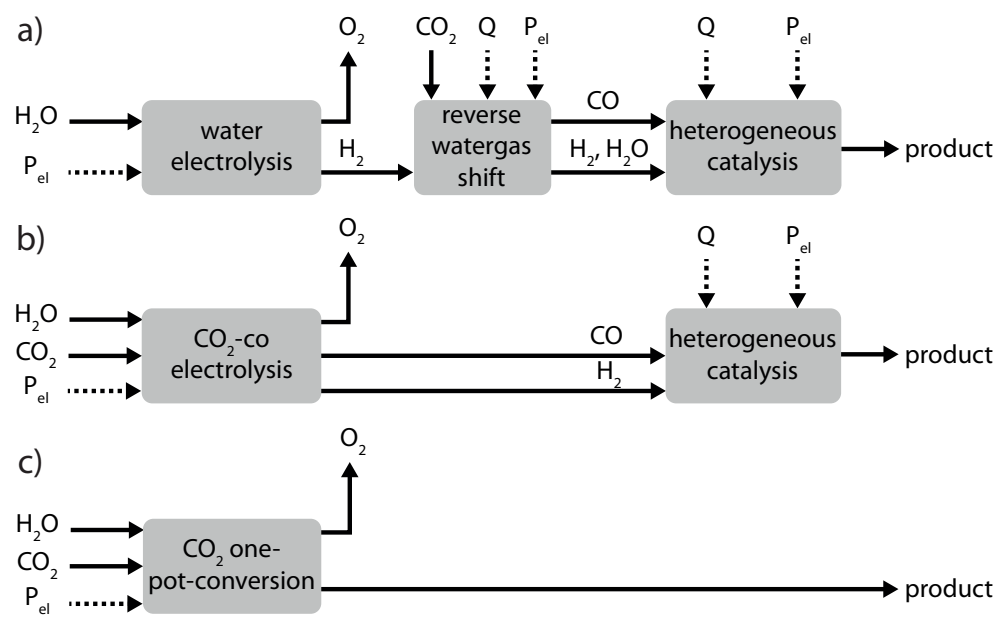

Figure 1: Different pathways for the conversion of $\mathrm{CO}_{2}$ into valuable products with electrochemical membrane reactors. Process scheme a) is suggested for the industrial integration of renewable energies in the chemical industry. It is a three-stage process consisting of water electrolysis followed by a reverse watergas shift and finally a heterogeneous catalysis for product synthesis. In process scheme b), a two-stage process, water electrolysis and reverse watergas shift are integrated to form synthesis gas, which is fed to the heterogeneous catalysis. Process scheme c) shows the direct conversion of $\mathrm{CO}_{2}$ to valuable products in a one-step process.

\section{Introduction}

Today, the field of research on the electrochemical reduction of $\mathrm{CO}_{2}$ grows continuously in relevance and extent. Limited fossil resources drive research on alternative technologies that could provide a renewable feedstock for the chemical and energy industry. Additionally, the growing world population and emerging economies demand an increasing amount of resources [1]. Out of the many proposed alternatives to oil, gas and coal, the electrochemical $\mathrm{CO}_{2}$ reduction stands out as one of the most promising candidates: the electrochemical activation of $\mathrm{CO}_{2}$ provides carbon-based platform chemicals and closes the anthropogenic carbon cycle mitigating net $\mathrm{CO}_{2}$ emissions [2,3]. An associated benefit of electrolysis processes is the feasibility of dynamic operation: The transient reactor operation balances the fluctuating energy output of renewable energies as demand meets supply. Consequently, the electrolysis stores energy supplied by renewable resources in times of excess [4].

Three different process schemes for the electrochemical valorization of $\mathrm{CO}_{2}$ are shown in Figure 1. The conventional route leads to the formation of synthesis gas (SG) and products derived thereof, see Figure 1 a). Here, a polymer electrolyte membrane (PEM) or alkaline wa- 
ter electrolysis is followed by reverse water-gas shift (RWGS) reaction. Value-added products are then obtained by conventional heterogeneous catalysis [5]. Depending on the product, a two-stage production is possible. For instance, methanol formation can be combined with the RWGS reaction in one step. Nevertheless, a drawback of scheme a), whether as a twoor three-stage process, is the multistage approach with heat transfer (including high exergy losses) and energy-intensive gas compression processes [6]. Ideally, a one-step process in an electrochemical membrane reactor (ecMR) process yields fuels or chemicals directly, see Figure $1 \mathrm{c}$ ). Electrochemical valorization of $\mathrm{CO}_{2}$ would allow operation at mild conditions of temperatures below $100^{\circ} \mathrm{C}$ and pressures below 10 bar with low associated exergy losses from renewable energies like wind or solar. Though it is generally feasible to reduce $\mathrm{CO}_{2}$ directly to fuels, implementation is hampered by low selectivity and consequently low energetic efficiency $[7,8,9]$. The most promising route is the co-electrolysis of $\mathrm{CO}_{2}$ to $\mathrm{SG}$, see process scheme b). In this process, $\mathrm{CO}_{2}$ is electrochemically reduced to carbon monoxide (CO) while hydrogen $\left(\mathrm{H}_{2}\right)$ is formed as side product $[10,11]$. This scheme would allow a diverse use of $\mathrm{SG}$ for different processes and products. Scheme b) is a compromise of a) and c) as it reduces the number of reaction stages but circumvents the complexity of c).

The products of the electrochemical $\mathrm{CO}_{2}$ co-electrolysis depend on the type of catalyst and hence almost all research focuses on catalyst development. Hori and co-workers classified the active metal electrocatalysts for $\mathrm{CO}_{2}$ reduction into four groups:

- The non-noble metals indium, lead, cadmium and tin are highly active towards formic acid $(\mathrm{HCOOH})$ formation. The tendency to bind $\mathrm{CO}_{2}$ is very low and thus the reduction is thought to take place through an outer-sphere mechanism [12].

- Gold, silver $(\mathrm{Ag})$ and zinc bind $\mathrm{CO}_{2}$ to varying degrees, but cannot reduce $\mathrm{CO}$ further and are consequently active towards CO formation [12].

- Even though copper $(\mathrm{Cu})$ binds $\mathrm{CO}_{2}$ moderately as well, it is the only metal which is able to protonate adsorbed $\mathrm{CO}$ (to either ${ }^{*} \mathrm{COH}$ or ${ }^{*} \mathrm{CHO}$ ) [13]. The products 
highly depend on the $\mathrm{Cu}$ surface orientation. $\mathrm{Cu}(100)$ favors ethylene $\left(\mathrm{C}_{2} \mathrm{H}_{4}\right), \mathrm{Cu}(111)$ methane $\left(\mathrm{CH}_{4}\right)$ while $\mathrm{Cu}(110)$ shows increased yields of alcohols and non-gaseous $\mathrm{C}_{2}$ and $\mathrm{C}_{3}$ products. Additionally, the product spectrum is strongly affected by the applied electrode potential [12, 14, 15, 2, 16].

- The platinum group metals including titanium, nickel and iron form $\mathrm{H}_{2}$ with very high current efficiency as a consequence of the strong CO adsorption [12]

Next to heterogeneous metal catalysts, tunable molecular catalysts (metal organic complexes) have received considerable attention due to their high activity and selectivity. However, even though efforts were made to increase the stability in aqueous media by the incorporation into covalent organic frameworks, this field is still emerging [17, 18]. Other electrocatalysts are metal oxides, metal chalcogenides and heteroatom-doped carbons [3].

Compared to the vast amount of research on catalysts, few studies have focused on cell design, the configuration of electrodes as well as the batch compared to flow-mode operation, which are of considerable importance for a stable performance, an energetic efficient transformation and the product spectrum [19]. Even though researchers have turned their spotlight on some individual aspects, a comprehensive analysis is missing. Here, we present a systematic methodology to evolve beyond the catalyst. An analysis encompassing electrochemical membrane reactor design aspects such as catalysts, electrodes and cell configurations will be presented. Only a minor fraction of published work focuses on $\mathrm{CO}_{2}$ reduction in continuous flow mode. Most of these few publications concentrate on the optimization of process conditions rather than the cell design [20].

In this work, we provide an extensive study of ecMR designs pursuing high production rates (respectively high current densities) relevant for industrial processes and tunable product spectra. The current efficiency and the energetic efficiency represent the two key performance indices in the study. Increasing the energetic efficiency in a cation exchange membrane based ecMR by decreasing the catholyte gap is feasible, but only non-zero-gap configurations yield a high current efficiency. In a zero-gap arrangement the acidic Nafion 


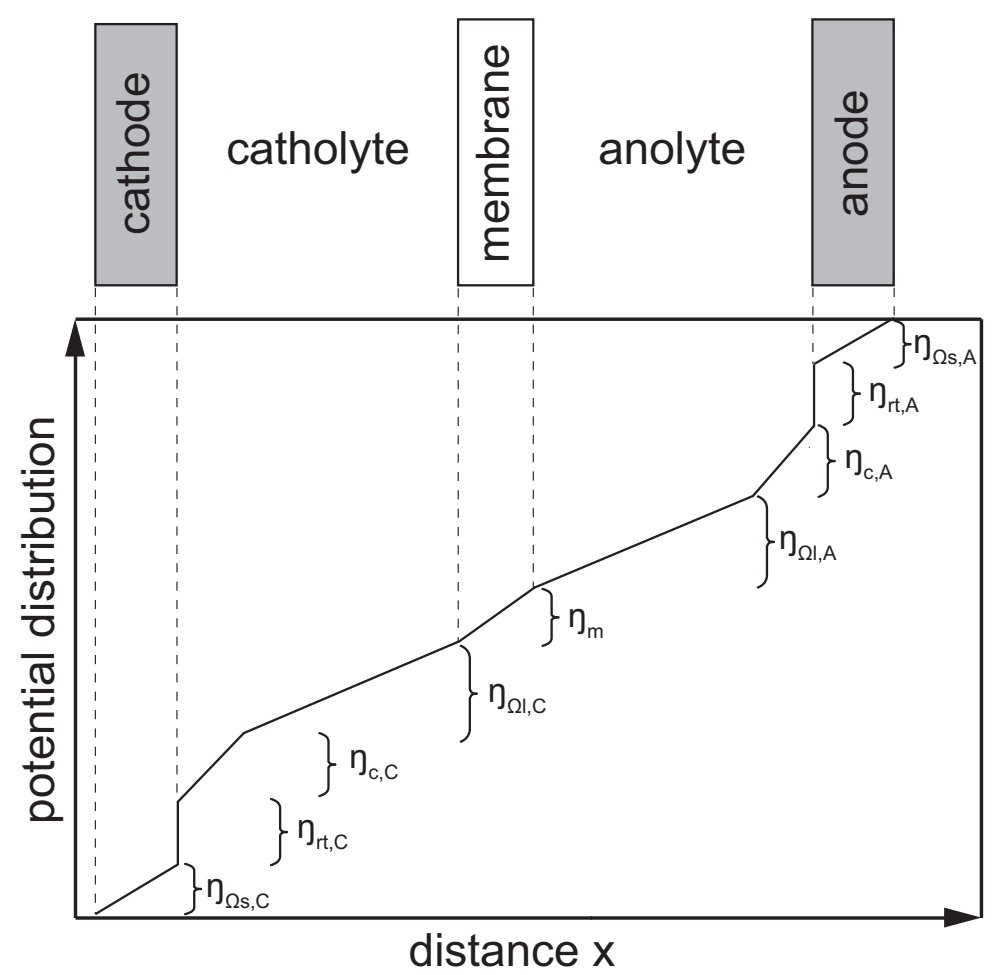

Figure 2: Potential distribution in a symmetrical ecMR with two liquid electrolytes separated by a central membrane.

membrane environment favors the hydrogen evolution reaction while suppressing the formation of any other product [10]. We analyze the influence of a nanoparticulate catalyst opposed to full metal electrodes and underline the importance of gas diffusion electrodes (GDE). The benefit of continuous operation in terms of liquid and gaseous product removal and defined electrolyte hydrodynamics is pointed out. Furthermore, our data demonstrate the feasibility of a continuous one-pot synthesis of hydrocarbon fuels in the form of $\mathrm{C}_{2} \mathrm{H}_{4}$.

\subsection{Design aspects of ecMR for $\mathrm{CO}_{2}$ reduction}

In this study, the overall cell reaction comprises the $\mathrm{CO}_{2}$ reduction to $\mathrm{CO}$ and $\mathrm{C}_{2} \mathrm{H}_{4}$ at the cathode, with $\mathrm{H}_{2}$ formation as a by-product, and the oxygen evolution reaction (OER) at the anode. The OER supplies the protons for $\mathrm{CO}_{2}$ reduction while the current source supplies electrons. An efficient ecMR $\mathrm{CO}_{2}$ reduction can be obtained by optimizing the anode and the cathode compartment individually, but cross-influences like $\mathrm{CO}_{2}$ insertion strategies should not be neglected as will be shown. The anodic reaction and cell compartment in this study (at 
least for some reactor configurations) are similar or identical to the PEM water electrolysis. An optimization of this half cell reaction has been extensively reviewed, including the choice of catalyst, set-up and design [21]. The present work will mainly focus on the optimization of the cathode side. Of course, the overall cell design highly influences the necessary total cell potential. The performance of the investigated ecMRs will be evaluated based on the current density (CD), current efficiency (CE) and energetic efficiency (EE).

The EE can be calculated by comparing the chemically-bonded energy leaving the system to the supply of electrical energy. The EE is a function of the different CEs $\left(\eta_{\mathrm{CE}, \mathrm{i}}\right)$ connected to their individual thermoneutral voltages, see Equation 1. A detailed derivation of the equation can be found in the SI.

$$
\eta_{E E}=\frac{1.46 \mathrm{~V} \cdot \eta_{C E, C O}+1.48 \mathrm{~V} \cdot \eta_{C E, H_{2}}+1.21 \mathrm{~V} \cdot \eta_{C E, C_{2} H_{4}}}{E_{c e l l}}
$$

Equation 1 leads to the impression as if $\eta_{\mathrm{EE}}$ only depends on the cell potential $\left(\mathrm{E}_{\mathrm{cell}}\right)$. Of course, $E_{\text {cell }}$ is linked to the current flowing through the cell, which is highly dependent on its design. Design aspects influencing the different energy losses will be discussed here in detail. The different overpotentials in an ecMR are shown in Figure 2. On the cathode side the ohmic potential drop of the electrode $\left(\eta_{\Omega \mathrm{s}, \mathrm{C}}\right)$, the overpotential for the cathode reaction $\left(\eta_{\mathrm{rt}, \mathrm{C}}\right)$, the concentration overpotential $\left(\eta_{\mathrm{c}, \mathrm{C}}\right)$, the iR-drop of the catholyte $\left(\eta_{\Omega \mid, C}\right)$ and the iRdrop over the membrane $\left(\eta_{\mathrm{m}}\right)$ can be identified. The same overpotentials apply for the anode side. In Table 3 the individual overpotentials of the cathode side and their main influencing factors are given. The ambitious goal of this work is to identify the factors influencing the different overpotentials to minimize these. In the end, this will yield an energetic efficient ecMR with a high $\mathrm{CE}$ for $\mathrm{CO}_{2}$ reduction products for high CDs. 


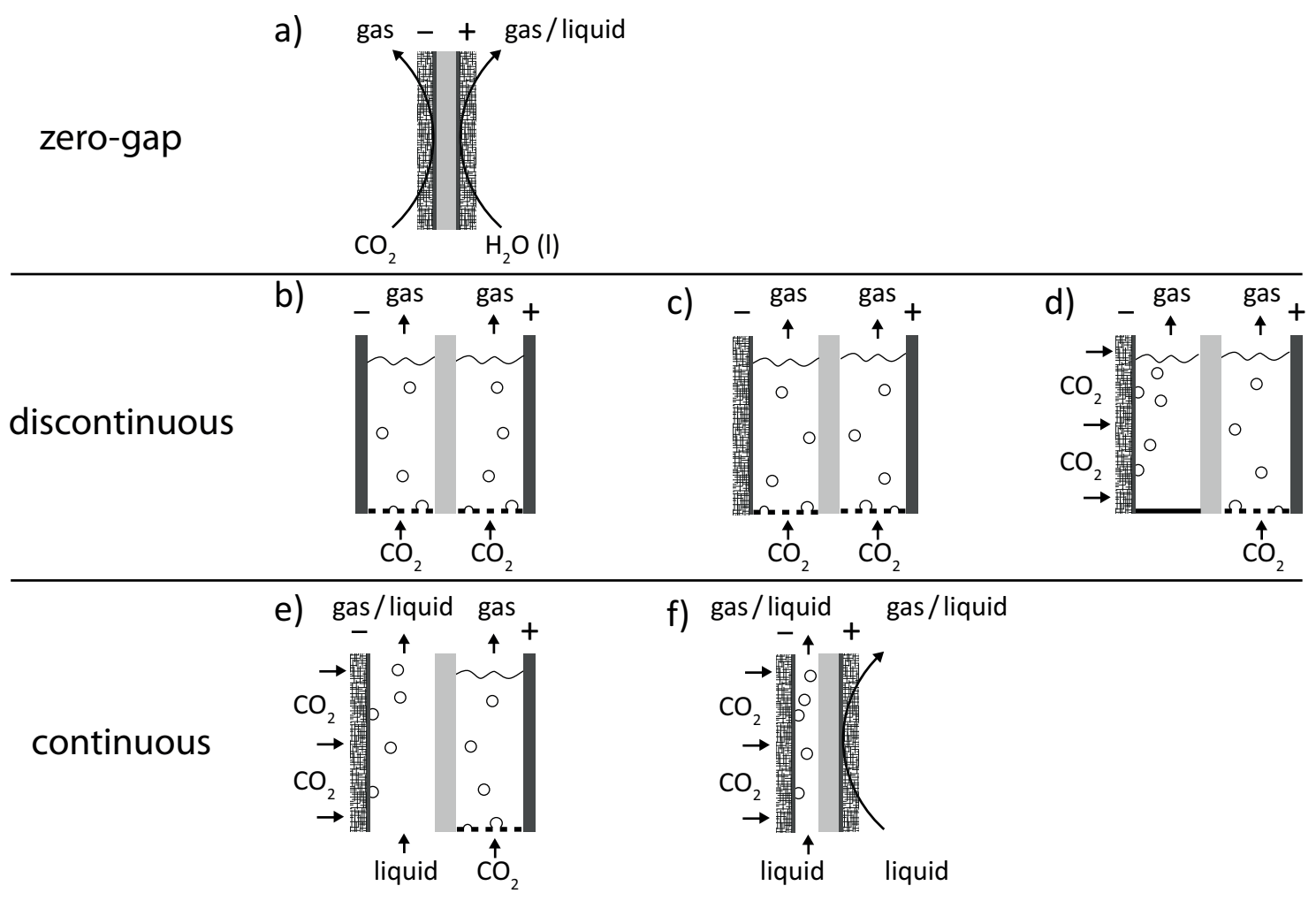

Figure 3: Different electrochemical membrane reactor designs for the $\mathrm{CO}_{2}$ activation. Scheme a) shows a zero-gap assembly without a liquid electrolyte. Scheme b) through d) are discontinuous set-ups with liquid electrolytes and different types of electrodes and means to supply $\mathrm{CO}_{2}$ to the system. Scheme e) is a halfcontinuous system using a gas diffusion electrode as cathode. Scheme f) aims at an energetic efficient $\mathrm{CO}_{2}$ with a zero-gap configuration at the anode and a decreased cathodic buffer layer thickness.

Table 3: The different overpotentials in an ecMR and their main influencing factors. Only cathodic overpotentials are shown but the same apply for the anode side.

\begin{tabular}{l|l} 
overpotential & main influencing factor \\
\hline \hline$\eta_{\Omega \mathrm{s}, \mathrm{C}}$ & electrode design \\
$\eta_{\mathrm{rt}, \mathrm{C}}$ & electrode and ecMR design \\
$\eta_{\mathrm{c}, \mathrm{C}}$ & ecMR design \\
$\eta_{\Omega \mathrm{I}, \mathrm{C}}$ & ecMR design \\
$\eta_{\mathrm{m}}$ & choice of membrane \\
\hline
\end{tabular}




\section{Materials and methods}

\subsection{Cell design considerations}

Different ecMR configurations are compared in this study to identify the most promising design for the co-electrolysis of $\mathrm{CO}_{2}$ in terms of EE. The designs range from a conventional liquid-liquid electrolysis system with full metal electrodes to a fuel cell like system, see Figure 3. First, the design adopted from fuel cells will be evaluated since it shows the least ohmic losses and thus probably the most promising EE, see Figure 3 set-up a). To understand the individual influencing factors on $\mathrm{CO}_{2}$ reduction performance, the nanoparticulate electrode is compared to a full metal electrode in a conventional batch liquid-liquid system saturated with $\mathrm{CO}_{2}$ (set-up c)). Subsequently, the cathode is changed to a GDE to study the benefits of the three phase boundary (set-up d)). Continuous flow-through operation opposed to batch operation yields defined liquid and gaseous product removal out of the ecMR, easy temperature control and improved hydrodynamics (set-up e)). Overpotentials at the anode side are mitigated by changing the anode configuration from a buffered set-up to a zero-gap assembly, set-up f). Step by step, individual parts of the ecMR are investigated and display their influence on achievable specific production rates of $\mathrm{CO}_{2}$ reduction products. It is the aim to decrease the different overpotentials by the right design of the reactor and the cathode to increase the EE while keeping the CD and the CE as high as possible.

\subsection{Experimental setup}

A flow sheet of the experimental setup is included in Figure 4. All chemicals used for the electrolyte solutions were ACS grade or better. Solutions were always freshly prepared with deionized water $(18.2 \Omega \mathrm{cm})$. In all designs a $0.5 \mathrm{M} \mathrm{K}_{2} \mathrm{SO}_{4}$ electrolyte was used, except in the experiments with a catalyst coated membrane (CCM) at the anode side, where deionized water was used. All parts in contact with the electrolytes were cleaned with deionized water prior to and after usage. For all experiments $\mathrm{CO}_{2}$ with a purity of $99.995 \%$ was 


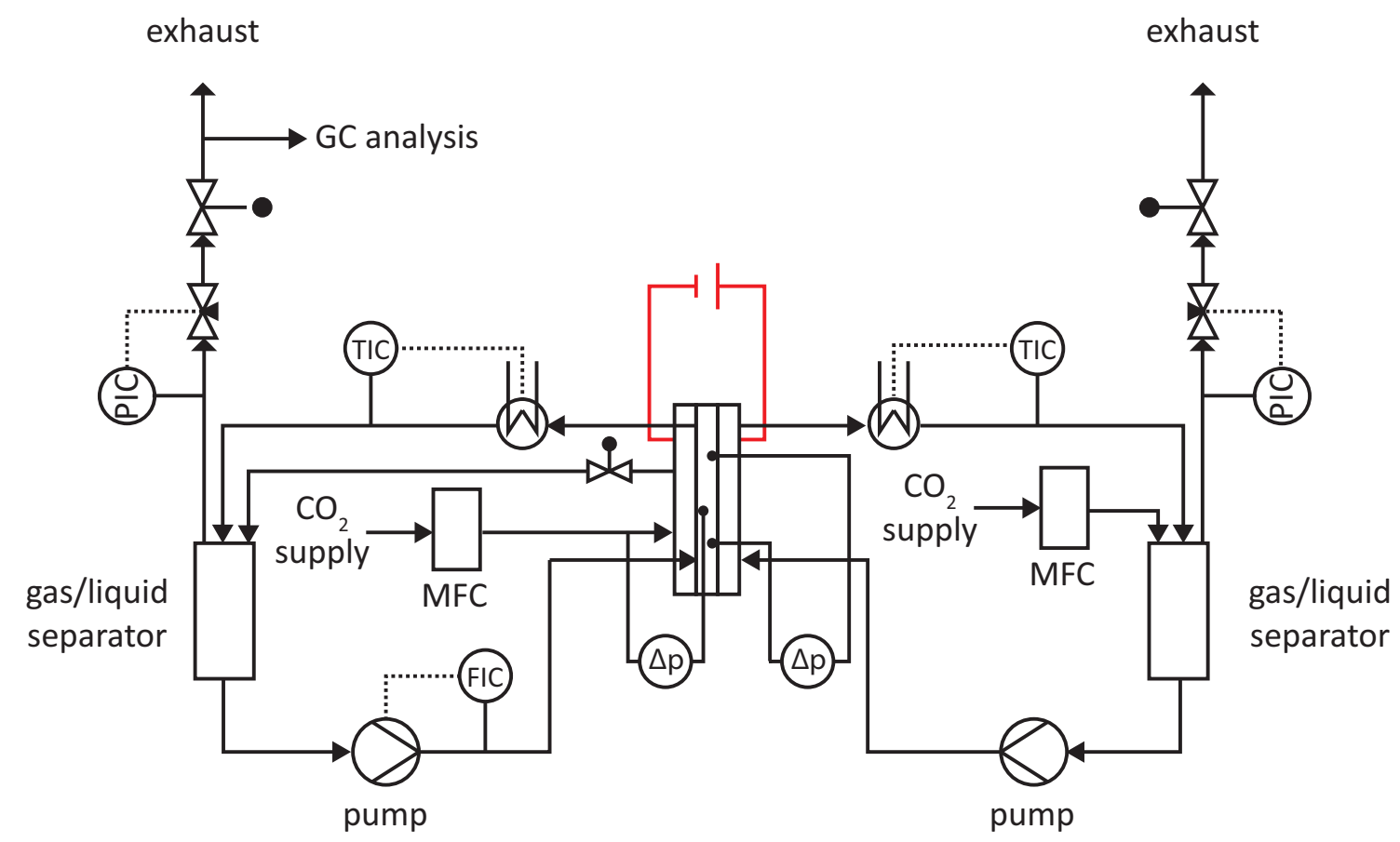

Figure 4: Experimental set-up for $\mathrm{CO}_{2}$ reduction with the cathodic cycle on the left, the anodic cycle on the right and the electrochemical membrane reactor with the current supply (red connection) in the middle. $\mathrm{CO}_{2}$ flow control, absolute pressure as well as differential pressure control and GC analysis is integrated. Both cycles allow for optional continuous and temperature controlled operation.

used. The gas flow was kept constant with a mass flow controller at $4.5 \mathrm{sccm} \mathrm{min}^{-1} \mathrm{~cm}^{-2}$. For batch mode operation, the electrolyte chamber was filled with $10 \mathrm{ml}$ electrolyte which was replaced after every CD. For the continuous experiments the electrolyte volume was fixed at $150 \mathrm{ml}$ and recycled over the complete course of the experiment. A Fumapem F14100 (Fumatech) cation exchange membrane (CEM) separated anolyte and catholyte in all reactor configurations. Silver and copper full metal electrodes as well as nanoparticulate GDEs were used. The GDEs were based on a gas diffusion layer by Freudenberg (GDL, Freudenberg, H2315 I2 C6) and the catalyst particles were bonded either with Fumion 14100 ionomer (Fumatech) or PTFE (Alfa Aesar). A detailed description of the electrode preparation can be found in the SI. 


\subsection{Cell designs}

\section{Zero-gap assembly}

The cell for process scheme a) was adopted from fuel cell technology. The active area on both sides was $20 \mathrm{~cm}^{2}$. A CEM separated the anode from the cathode cell body. At the anode side a titanium felt by Bekaert was used as the current collector while at the cathode side the Freudenberg GDL served as the current collector. The cathode catalyst was coated on the GDL and subsequently hot-pressed onto the membrane at $135^{\circ} \mathrm{C}$ at a pressure of 450 bar. Both titanium cell bodies had machined flow fields for educt and product transport. Furthermore, a connection to a salt bridge was integrated in the anode cell body to measure half cell potentials with a commercial reference electrode outside the cell. This reference electrode set-up allows monitoring electrode potentials in zero-gap assemblies with only a solid electrolyte [22]. All potentials were measured with a saturated $\mathrm{Ag} / \mathrm{AgCl}$ reference electrode by Meinsberg.

Two-sided buffered assembly

A self-made electrochemical cell made from acrylic glass with flat sheet gaskets was used in the processes b) - e). Working and counter electrode faced each other for a uniform potential distribution. The active area of the working electrode (cathode) was $4.5 \mathrm{~cm}^{2}$ and the active area of the anode $9.0 \mathrm{~cm}^{2}$. Anolyte and catholyte were separated by the CEM to avoid mixing. The reference electrode was placed in the middle of the catholyte compartment (20 mm width) to individually monitor electrode potentials. For the conventional $\mathrm{CO}_{2}$ reduction, process b) and c), $\mathrm{CO}_{2}$ could be inserted via small PTFE tips at the bottom of the cell in the vicinity of the electrode to saturate the solution and enhance convective mixing. For experiments using GDEs, set-up d) to e), $\mathrm{CO}_{2}$ was supplied to the backside of the GDE. Continuous electrolyte flow, set-up e), was realized with a cell compartment with inlet and outlet connection.

\section{One-sided buffered assembly}

For process scheme f) a self-made cell housing a GDE was used. The cell was made out of polycarbonate. All electrically conducting parts were made of titanium. The anode was a 
CCM with an active area of $20 \mathrm{~cm}^{2}$. The CCM was connected to the anode cell body by a sintered porous titanium sheet (GKN T10 filter metal). Two connections at the backside of the anode cell body allowed continuous reactant and product removal. Furthermore, a connection to a salt bridge was integrated to measure half cell potentials with a reference electrode similar to set-up a). The anode compartment was separated from the cathode compartment by the membrane. The cathode compartment consisted of a flat sheet gasket with room for a spacer. A GDE could be attached to the buffer layer with its active side by a $0.1 \mathrm{~mm}$ thick PTFE gasket to define the active area and seal it from the electrolyte inand outflow. The distance between GDE and membrane was fixed with a commercial Naltex spacer to $0.5 \mathrm{~mm}$. The backside of the GDE was in contact with the titanium inlay in the cathode cell body which was equipped with a flow field for $\mathrm{CO}_{2}$ supply.

\subsection{Electrolysis experiments}

An Autolab 302N (Methrom) potentiostat with a FRA impedance module was used for all the electrochemical measurements. All experiments were executed in galvanostatic mode, with each current applied for 2800 s. During this time five samples could be analyzed via online gas chromatography-mass spectrometry (GC/MS). The first two samples were discarded as they were influenced by dilution effects. After each current step an impedance measurement was performed to compensate the working electrode potential for ohmic losses. Especially for the novel reference electrode set-up the IR compensation is important, as the potential distribution outside the active area of the electrodes is inhomogeneous [23]. For batch experiments the electrolyte was exchanged while no current was applied to the system. Electrolyte saturation in batch mode was performed for $10 \mathrm{~min}$ and in continuous mode for $30 \mathrm{~min}$. For continuous mode the temperature of the catholyte was fixed at $30^{\circ} \mathrm{C}$. If possible, polarization experiments will be presented as a function of the reversible hydrogen electrode (RHE) to take into account the different proton activities. The gaseous flow leaving the system was measured with a volumetric bubble flow meter by Supelco. As gaseous products were the target compounds of this work, $\mathrm{HCOOH}$ and other liquid phase 


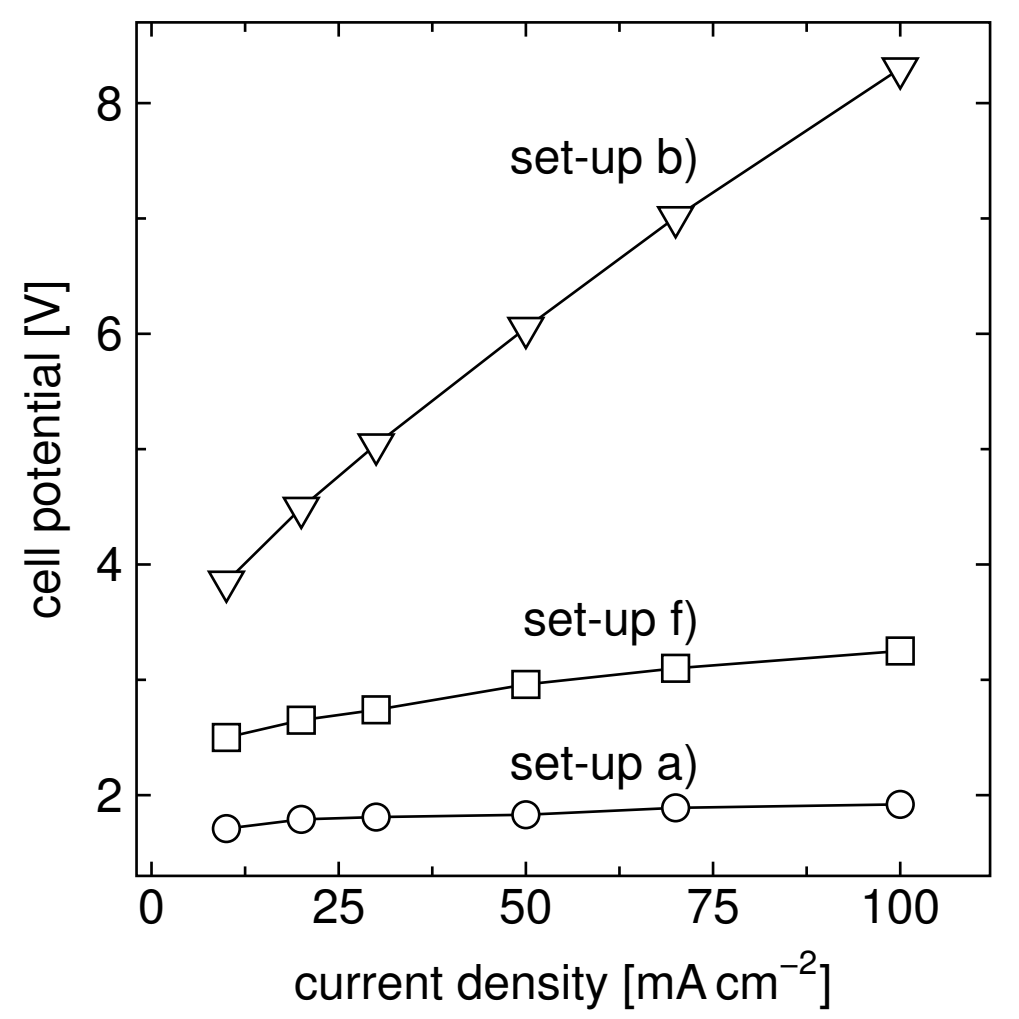

Figure 5: The cell potentials for different current densities respectively production rates are plotted for set-up a) (continuous zero-gap configuration with same solid electrolyte for both electrodes), set-up b) (discontinuous two-sided buffered configuration with blank metal electrodes) and set-up f) (fully continuous divided system using a $0.5 \mathrm{~mm}$ buffered gas diffusion electrode as cathode and a zero gap anode configuration).

products were not measured in the experiments. The experiments for $\mathrm{Ag} \mathrm{CO}_{2}$ reduction exhibit CEs in the range of $90-110 \%$. The $\mathrm{CE}$ for $\mathrm{Cu} \mathrm{CO}_{2}$ reduction experiments is in the range of 70-105\%. Especially at lower CDs the sum of CEs is around 70-80\%. This is due to the wide product range of $\mathrm{Cu} \mathrm{CO}_{2}$ reduction products which are as stated not all measured. In ongoing works we measured $\mathrm{HCOOH}$ as a major product at low CDs.

\section{Results and discussion}

\subsection{Energetic efficiency of different cell designs}

As shown in the previous section, the EE depends on $\mathrm{E}_{\text {cell }}$ for a fixed CD. Figure 5 shows the polarization behavior of set-up a), b) and f) for Ag-based electrodes. Set-up b) with liquid buffer layers at the anode and cathode shows the highest cell potentials. Regardless 


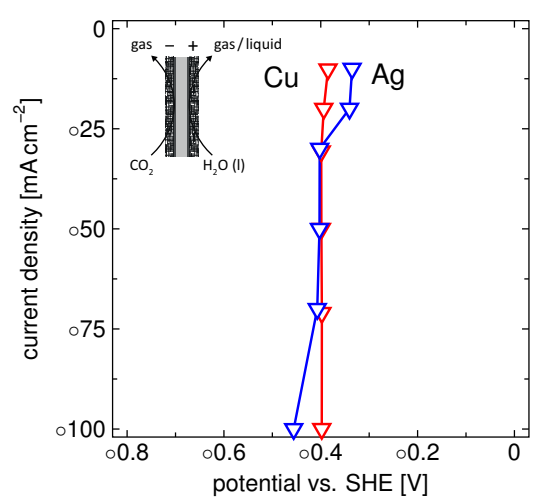

(a) Polarization for setup a) for the $\mathrm{Ag}$ PTFE-bonded and the $\mathrm{Cu}$ Nafionbonded GDEs

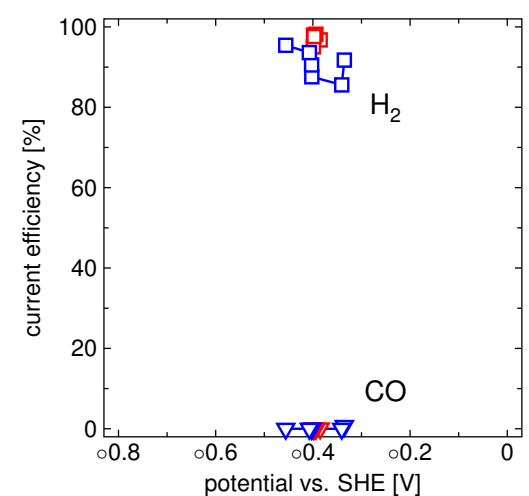

(b) Current efficiency for the Ag PTFEbonded and the $\mathrm{Cu}$ Nafion-bonded GDEs

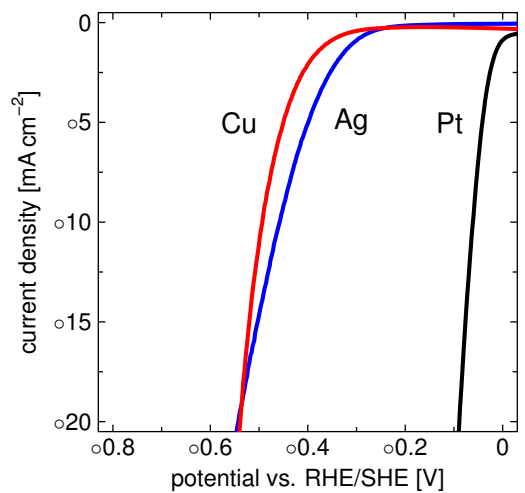

(c) Linear sweep voltammetry (non ohmic-drop compensated) in $0.5 \mathrm{M}$ $\mathrm{H}_{2} \mathrm{SO}_{4}$

Figure 6: $\mathrm{CO}_{2}$ reduction performance for a $\mathrm{Cu}$ Nafion-bonded and a $\mathrm{Ag}$ PTFE-bonded GDEs is shown for set-up a) and compared to a linear sweep voltammetry of the same electrodes in a pH-defined electrolyte.

of the products, the EE for the highest CD is as low as $18 \%$ (based on the thermoneutral voltage for water electrolysis $(1.46 \mathrm{~V}$ see SI)). Set-up a) with a fuel cell like design with no aqueous electrolyte between the membrane and the electrodes shows the lowest cell potentials as ohmic losses within the anolyte and catholyte are mitigated. EEs of over $77 \%$ are reached with set-up a) for CDs up to $100 \mathrm{~mA} \mathrm{~cm}^{-2}$. Compared to PEM water electrolysis this is low, but the co-electrolysis of $\mathrm{CO}_{2}$ aims at different products with different catalysts and thus different activation overpotentials $\eta_{\mathrm{rt}, \mathrm{C}}$. As expected, the performance of set-up f) is between a pure fuel cell type set-up and a two-sided buffered system. The EE is in the range of $46 \%$ for the highest applied CD. A decrease in buffer layer thickness between the cathode and the membrane would further mitigate the IR-drop, moving the slope of the polarization plot of system f) closer to a) and increase the EE.

The specific conductivity of the electrolyte and the membrane are both $\sim 93 \mathrm{mS} \mathrm{cm}^{-1}$. However, the electrolyte buffer layer thickness is orders of magnitude larger $(20 \mathrm{~mm})$ for setup b) compared to the membrane thickness $(0.1 \mathrm{~mm})$ and buffer layer thickness in set-up f) $(0.5 \mathrm{~mm})$. The calculation of the theoretical ohmic resistances for the different set-ups with their individual geometrical cell designs are given in Table 4 (assuming stable electrolyte performance). The non-ideal geometry due to reference electrode insertion and spacer are neglected in this calculation. The theoretical ohmic resistance decreases from $1.052 \mathrm{Ohm}$ 
Table 4: Theoretical calculations of the IR drops for the applied current densities for set-up a) (continuous zero-gap configuration with same solid electrolyte for both electrodes), set-up b) (discontinuous two-sided buffered configuration with blank metal electrodes) and set-up f) (fully continuous divided system using a $0.5 \mathrm{~mm}$ buffered gas diffusion electrode as cathode and a zero gap anode configuration). The theoretical ohmic resistance is $1.052 \mathrm{ohm}$ for the $20 \mathrm{~mm}$ gap, $0.263 \mathrm{ohm}$ for the $0.5 \mathrm{~mm}$ gap and $0.053 \mathrm{ohm}$ for the membrane. Additionally, the thermodynamically-based increase in cell potential as a result of a difference in anodic and cathodic pH via Nernst equation is given for set-ups b) and f) with different electrolytes at the anode and cathode side.

\begin{tabular}{l|c|c|c|c|c}
$\mathrm{CD}\left[\mathrm{mA} \mathrm{cm}^{-2}\right]$ & $\eta_{\Omega, \text { total set-up a) }}[\mathrm{V}]$ & $\eta_{\Omega, \text { total set-up b) }}[\mathrm{V}]$ & $\eta_{\text {rt, set-up b) } \Delta \mathrm{pH}}[\mathrm{V}]$ & $\eta_{\Omega, \text { total set-up f) }}[\mathrm{V}]$ & $\eta_{\text {rt, set-up f) } \Delta \mathrm{pH}[\mathrm{V}]}$ \\
\hline \hline 10 & 0.001 & 0.422 & 0.289 & 0.006 & 0.326 \\
20 & 0.002 & 0.843 & 0.313 & 0.013 & 0.350 \\
30 & 0.003 & 1.266 & 0.341 & 0.019 & 0.373 \\
50 & 0.005 & 2.111 & 0.358 & 0.032 & 0.390 \\
70 & 0.007 & 2.955 & 0.372 & 0.044 & 0.405 \\
100 & 0.011 & 4.221 & 0.382 & 0.063 & 0.424 \\
\hline
\end{tabular}

for the $20 \mathrm{~mm}$ gap to $0.263 \mathrm{Ohm}$ for the $0.5 \mathrm{~mm}$ gap down to $0.053 \mathrm{Ohm}$ for the membrane alone. This results in different IR drops for increasing CDs and thus a different slop of the cell polarization, see Figure 5. An IR drop for set-up b) of $4.221 \mathrm{~V}$ compared to $0.063 \mathrm{~V}$ for set-up f) and only $0.0105 \mathrm{~V}$ for set-up a) can be calculated for $100 \mathrm{~mA} \mathrm{~cm}^{-2}$.

Additionally, a difference in cathodic and anodic $\mathrm{pH}$ in set-up b) and f) leads to even higher cell potentials and thus limitations in EE. A difference in $\mathrm{pH}$ for set-up b) leads via Nernst equation to a thermodynamically based increase in cell potential of $0.382 \mathrm{~V}$ at $100 \mathrm{~mA} \mathrm{~cm}^{-2}$ (see $\mathrm{pH}$ in SI). With the assumption of a $\mathrm{pH}$ of 0 for the CCM an increase in cell potential of $0.424 \mathrm{~V}$ has to be considered for set-up f). For set-up a) the $\mathrm{pH}$ at the anode and cathode should ideally be equal and thus no extra increase in cell potential should result. Additionally, the anode in set-up b) is sluggish compared to the highly porous GDE based on $\mathrm{IrO}_{2}$ nanoparticles in a) and f). Compared to a flat sheet titanium electrode with a thin active layer of platinum these electrodes are characterized by a lower $\eta_{\mathrm{rt}, \mathrm{A}}$ : Firstly, platinum shows higher activation overpotentials for OER compared to $\mathrm{IrO}_{2}[24]$ and secondly, the type of electrode shows less active sites which results in in higher electrode potentials for the same applied CD. These differences in catalyst and $\mathrm{pH}$ might explain the differences in y-axis intercept between set-ups a), b) and f). 
For an energetically efficient reduction of $\mathrm{CO}_{2}$ the cell potential should be as low as possible. The lower the cell potential the more electrically-bonded energy is converted to chemically-bonded energy and energy losses are suppressed. However, there is a trade off between EE and CE: If the anode catalyst is directly pressed to the acidic environment of the Nafion membrane, high EEs can only be reached, if the cathode is in a highly acidic environment as well (to keep anodic and cathodic $\mathrm{pH}$ nearly identical). However, $\mathrm{CO}_{2}$ reduction at these $\mathrm{pH}$ values is hampered by the unfavorable $\mathrm{H}^{+}$to $\mathrm{CO}_{2}$ ratio as we will explain in the next section.

\section{2. $\mathrm{CO}_{2}$ reduction in a zero-gap configuration (set-up a))}

From the previous section it is clear that set-up a) is the most desirable in terms of EE. However, this is not necessarily the best design for the production of SG or hydrocarbons. Polarization and $\mathrm{CE}$ data for $\mathrm{Ag}$ and $\mathrm{Cu}$ catalysts are plotted in Figures 6a and 6b. The onset potentials for the $\mathrm{Ag}$ and $\mathrm{Cu}$ catalysts are about $-0.34 \mathrm{~V}$ vs SHE for the former and $-0.39 \mathrm{~V}$ vs SHE for the latter, with a subsequent steep increase in CD. In this work, we assign the onset potential to the polarization potential at the lowest applied CD of $-10 \mathrm{~mA} \mathrm{~cm}^{-2}$. The polarization behavior for set-up a) is desirable as it yields high EE as reported. Nonetheless, the $\mathrm{CE}$ for $\mathrm{H}_{2}$ is nearly $100 \%$ for both $\mathrm{Ag}$ and $\mathrm{Cu}$. Two possible explanations for this performance are the acidic Nafion environment at the GDE surface and flooding of the electrode due to the water drag resulting from $\mathrm{H}^{+}$transport through the membrane.

In this paragraph we provide support for the first hypothesis: To determine the kinetic overpotential $\left|\eta_{\text {kin,HER }}\right|$ for the HER of the $\mathrm{Cu}$ and Ag catalyst, linear sweep voltammetry (LSV) experiments in a $0.5 \mathrm{M} \mathrm{H}_{2} \mathrm{SO}_{4}$ solution were performed and the results are plotted in Figure 6c. With the kinetic overpotential from the LSV experiments we can calculate the pH value in the zero-gap configuration system at the membrane via the Nernst equation using

the data from Figure 6. For $\mathrm{Cu}$ and $\mathrm{Ag}\left|\eta_{\text {kin,HER }}\right|$ in the LSV experiments is in the range of $300 \mathrm{mV}$ to $400 \mathrm{mV}$. With $0 \mathrm{~V}$ vs SHE the standard potential $\mathrm{E}_{0}$ for $\mathrm{HER}$ in $\mathrm{pH}=0$ and the 
onset potential $\left(\mathrm{E}_{\text {onset }}\right)$ of $-335 \mathrm{mV}$ to $-385 \mathrm{mV}$ for the lowest applied $\mathrm{CD}$ in the zero-gap assembly, the $\mathrm{pH}$ value at the active sites can be calculated:

$$
\begin{aligned}
E_{\text {onset }} & =E_{0}-0.059 \cdot p H-\left|\eta_{\text {kin }, H E R}\right| \\
p H & =\frac{E_{0}-\left|\eta_{k i n, H E R}\right|-E_{\text {onset }}}{0.059} \\
p H & \sim(-1) \text { to }(+1)
\end{aligned}
$$

Accordingly, both PTFE-bonded and Nafion-bonded GDEs are embedded in a very acidic environment. The direct contact to the Fumion membrane with its fixed sulfonic acid groups probably leads to this low $\mathrm{pH}$. Measurements with a very similar cell set-up for water electrolysis confirm the low $\mathrm{pH}$ next to the membrane environment for platinum electrodes with nearly no activation overpotential for HER and support our hypothesis [22]. Further proof for a suppressed $\mathrm{CO}_{2}$ reduction in different $\mathrm{pH}$ defined solutions is given in the $\mathrm{SI}$ and by Yano [25]. A clear trend to a favored HER for low $\mathrm{pH}$ values is observed. This is probably a result of a rather low mass transport of $\mathrm{CO}_{2}$ (as a result of the low solubility at standard conditions) to the active sites compared to the fast supply of protons out of the solution [26]. Further, if the $\sim 1 \mathrm{M}$ concentration of protons at ambient conditions is compared to the $3.3 \mathrm{~m} \mathrm{M}$ physically dissolved $\mathrm{CO}_{2}$ concentration (which is the only electrochemical active $\mathrm{CO}_{2}$ species) it is obvious that proton availability and diffusion to the electrode will be much faster than for $\mathrm{CO}_{2}[27,3]$. An additional drawback of the low $\mathrm{pH}$ is the corrosion of $\mathrm{Cu}$ under these conditions. Only short polarization times are possible, since $\mathrm{Cu}$ GDEs are not stable in the acidic environment, even when under protective cathodic polarization. The carbon backbone structure of the GDL might show some activity at this point, while $\mathrm{Cu}$ is oxidized. Ag shows superior stability in the acidic Nafion environment and allows long term polarization experiments, but is also not active towards $\mathrm{CO}_{2}$ reduction.

Flooding of the cathode by the water drag from the anode side is a challenge known from fuel cell operation. Every $\mathrm{H}^{+}$roughly drags 2.5 molecules of water through the membrane. 
[28] This leads to flooding of the GDE and thus prevents $\mathrm{CO}_{2}$ from diffusing to the three phase boundary. The right choice of hydrophilic and hydrophobic binder in the active porous GDE structure can counteract flooding. Such techniques are applied in fuel cell technology.

Nevertheless, the proximity of the acidic membrane does not allow a high CE. Interestingly, there are some publications with a zero-gap configuration or a anode-sided buffered system showing $\mathrm{CO}_{2}$ reduction products $[29,30]$. In most cases an activity was measured if cations different than $\mathrm{H}^{+}$were present in the anolyte. Then, non-reactive cations take part of the ionic current inside the membrane and thus mitigate the acidity. This phenomenon shows that the local $\mathrm{pH}$ inside the GDE has to be controlled to reduce $\mathrm{CO}_{2}$ using set-up a). Encouraging work is reported by Aeshala and Delacourt who use $\mathrm{Cu}$ or $\mathrm{Ag}$ in anionic solid polymer electrolytes $[10,31,32]$. The usage of anionic solid polymer electrolyte allows to create local basic $\mathrm{pH}$ values which suppress the HER and thus enable $\mathrm{CO}_{2}$ reduction. Nonentheless, an operation with anion exchange membranes incorporates challenges such as bicarbonate crossover and thus $\mathrm{CO}_{2}$ release at the anode.

As the fuel cell like system does not show any efficiency towards the desired products, other design aspects like the electrode and the $\mathrm{CO}_{2}$ supply of the ecMR will be stepwise examined to identify the most promising reduction set-up based on a CEM.

\section{3. $\mathrm{CO}_{2}$ reduction with full metal electrodes (set-up b))}

The polarization plots for flat full metal electrodes and the corresponding CEs are shown in Figure $7 \mathrm{a}$ and $7 \mathrm{~b}$. The polarization for $\mathrm{Cu} \mathrm{CO}_{2}$ reduction shows a typical exponential current-potential relationship. The onset potential of $-1.01 \mathrm{~V}$ vs RHE for $-10 \mathrm{~mA} \mathrm{~cm}^{-2}$ is comparable to data reported by other groups using $\mathrm{KHCO}_{3}$ as the electrolyte [15, 33]. The corresponding CE stays nearly constant at about $100 \%$ for $\mathrm{H}_{2}$ and thus nearly $0 \%$ for $\mathrm{CO}_{2}$ reduction. This result deviates from the $\mathrm{CE}$ observed in many studies for $\mathrm{CO}_{2}$ reduction on full metal electrodes. The observed performance might be a result of the high applied CDs and also fairly long experimental time which are thought to lead to a deactivation of the $\mathrm{Cu}$ electrode. The deactivation of $\mathrm{Cu}$ but also of $\mathrm{Ag}$ for the electrochemical reduction 


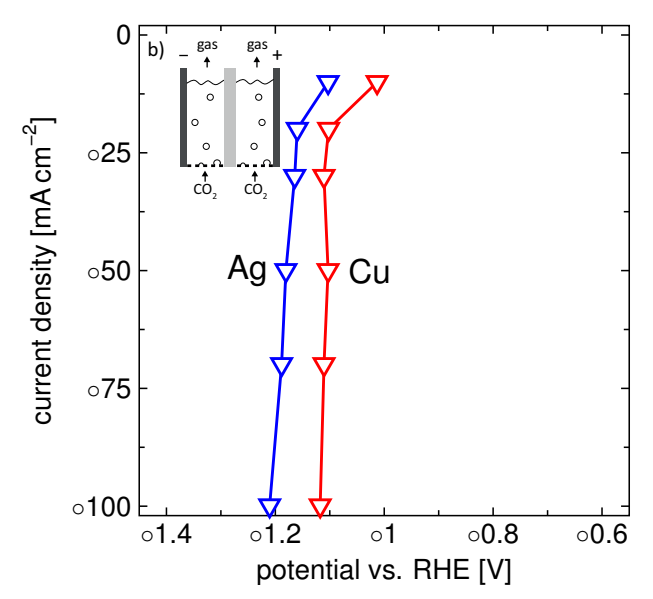

(a) Polarization for setup b) for full-metal electrodes

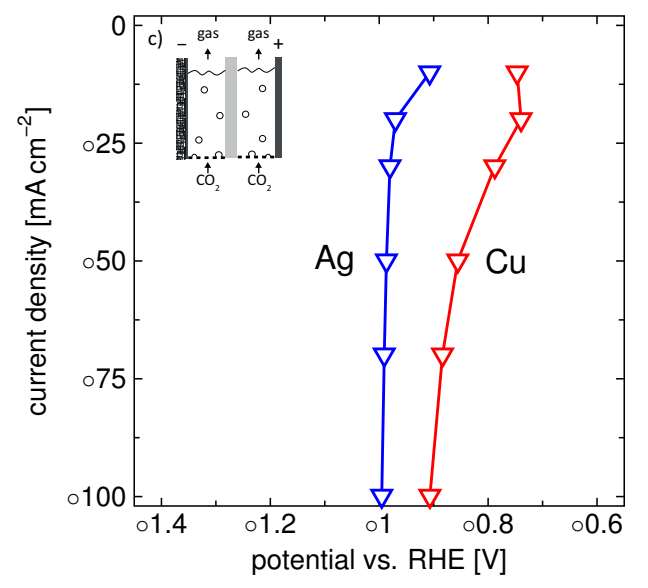

(c) Polarization for setup c) for the nanoparticulate electrode

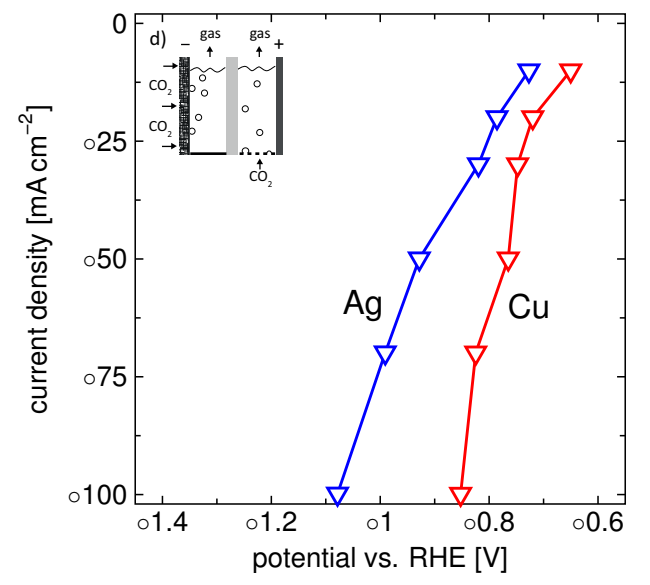

(e) Polarization for setup d) for Nafion-bonded GDEs

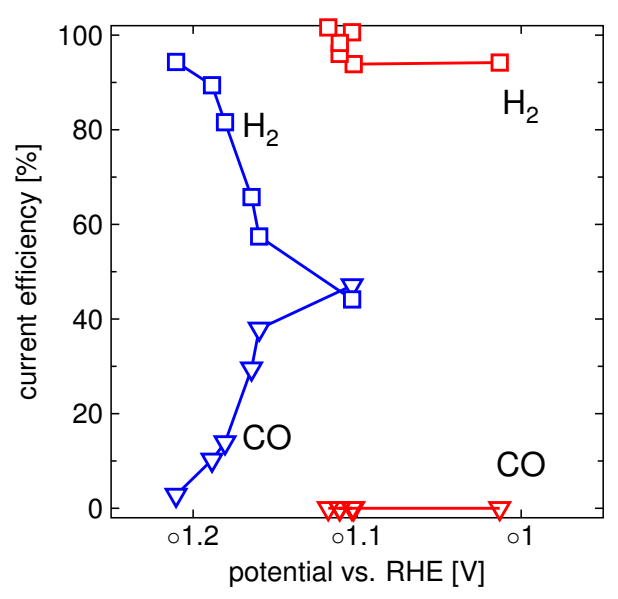

(b) Current efficiency for the full-metal electrodes

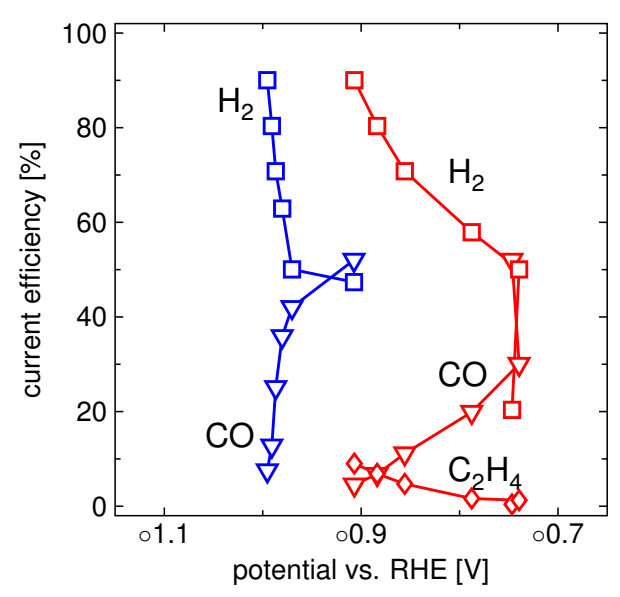

(d) Current efficiency for the nanoparticulate electrode

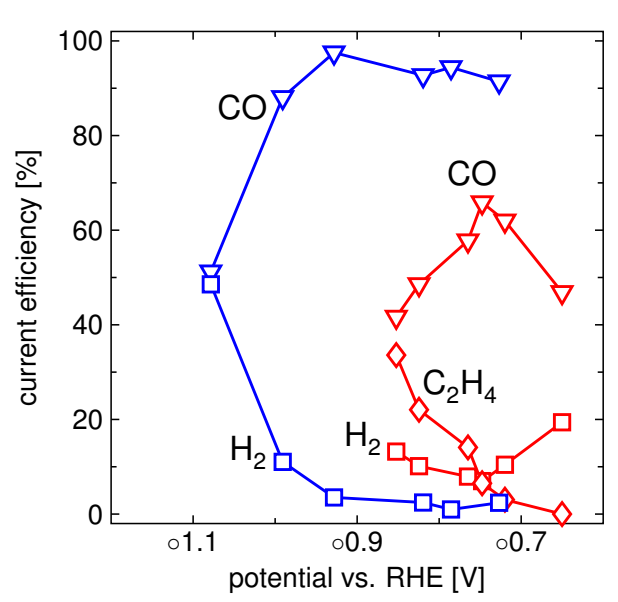

(f) Current efficiency for Nafion-bonded GDEs

Figure 7: Polarization plots for set-up b), c), and d). Current efficiencies for the full-metal electrode (set-up b)), the nanoparticulate electrode (set-up c)), and Nafion-bonded GDEs (set-up d)) are given. 
has not been completely understood yet, but $\mathrm{CO}_{2}$ reduction to inactive graphitic carbon is thought to be one reason $[34,25]$. Additionally, the reduction on full metal electrodes is very sensitive to the pretreatment [35]. The polarization plot of $\mathrm{Ag} \mathrm{CO}_{2}$ reduction resembles the one of $\mathrm{Cu} \mathrm{CO}_{2}$ reduction. For all $\mathrm{CDs}$, the potentials are reduced by roughly $100 \mathrm{mV}$ or more compared to $\mathrm{Cu}$ polarization. This can be explained by different $\left|\eta_{\text {kin }}\right|$ for different catalysts in $\mathrm{CO}_{2}$ reduction. The corresponding $\mathrm{CE}$ for the reduction on $\mathrm{Ag}$ decreases from $52 \%$ at $-10 \mathrm{~mA} \mathrm{~cm}^{-2}$ down to nearly zero at $-100 \mathrm{~mA} \mathrm{~cm}^{-2}$. This polarization behavior and performance in $\mathrm{CE}$ is similar to data reported in literature [36]. Mass transport limitations are assumed to be a major reason for the decreasing $\mathrm{CE}$, as $\mathrm{CO}_{2}$ has to diffuse from the bulk to the electrode surface [37].

\section{4. $\mathrm{CO}_{2}$ reduction with nanoparticulate electrodes (set-up c))}

A change from full metal electrodes to Fumion-bonded GDEs with nanoparticulate catalysts leads to different polarization behaviors and CEs, see Figures 7c and 7d. In set-up c), no gas is fed to the backside of the electrode. Nonetheless, changing characteristics due to the different electrocatalyst morphology can be observed. For $\mathrm{Cu} \mathrm{CO}_{2}$ reduction, the onset potential is at about $-0.75 \mathrm{~V}$ vs RHE compared to $-1.01 \mathrm{~V}$ vs RHE for the full metal electrode reduction, reducing $\eta_{\mathrm{rt}, \mathrm{C}}$ by $250 \mathrm{mV}$. With increasing electrode potential the CD increases exponentially. For $-100 \mathrm{~mA} \mathrm{~cm}^{-2}$ the potential is $-0.90 \mathrm{~V}$ vs RHE and thus $100 \mathrm{mV}$ reduced compared to the full metal electrode. The polarization does not show perfect exponential current potential behavior, which might be a result of undefined electrolyte penetration into the electrode. This results in an undefined electrochemical active surface area (not geometrical area). Interestingly, this set-up shows activity for $\mathrm{CO}_{2}$ reduction, at least for low CDs compared to full metal electrode experiments and Nafion-bonded GDEs in the zero-gap assembly. Although the GDE is in a Nafion matrix, there is a $\mathrm{CE}$ for $\mathrm{CO}_{2}$ reduction. The counter ion of the Nafion membrane is probably potassium $\left(\mathrm{K}^{+}\right)$, as the concentration of $\mathrm{K}^{+}$is some magnitudes higher than the $\mathrm{H}^{+}$concentration (the initial ratio of $\mathrm{K}^{+}$to $\mathrm{H}^{+}$is 
roughly $\left.1.0 \mathrm{M} / 1 \times 10^{-7} \mathrm{M}\right)$. Further, deactivation can be mitigated or even suppressed on nanoparticles opposed to polycrystalline electrodes [38]. For the lowest CD the CE is $52 \%$ for $\mathrm{CO}$ and then decreases to $4 \%$ at $-100 \mathrm{~mA} \mathrm{~cm}^{-2}$, whereas the $\mathrm{CE}$ for $\mathrm{C}_{2} \mathrm{H}_{4}$ increases from its initial value of $0.4 \%$ up to $9 \%$ at $-100 \mathrm{~mA} \mathrm{~cm}^{-2}$. In the beginning, the $\mathrm{CE}$ for $\mathrm{H}_{2}$ is as low as $20 \%$, but increases up to $90 \%$ for the highest CD. It is worth noting that the $\mathrm{CE}$ for $\mathrm{C}_{2} \mathrm{H}_{4}$ increases with increasing CD and thus more negative cathodic potential, whereas the CE for $\mathrm{CO}$ decreases. This shows a potential dependence for the $\mathrm{C}_{2} \mathrm{H}_{4}$ formation which is known from literature [7]. Methane could only be detected in traces which is probably a result of the nanoparticle electrocatalyst surface structure, see Chapter 1.

The $\mathrm{CE}$ for the $\mathrm{Cu} \mathrm{CO}_{2}$ reduction does not sum up to $100 \%$. From lowest to highest CD the sum is $73 \%, 81 \%, 79 \%, 86 \%, 94 \%, 104 \%$. It is known that at lower potentials liquid phase products form. This observation matches findings from our ongoing experiments and also from other groups who reported higher $\mathrm{HCOOH}$ formation at low CDs compared to high $\mathrm{CDs}[36,13]$. The $\mathrm{CE}$ for the $\mathrm{Ag} \mathrm{CO}_{2}$ reduction decreases for $\mathrm{CO}$, just like for the full metal electrode. From about $52 \%$ at the lowest CD it decreases to $7.5 \%$. The only other detected side product is $\mathrm{H}_{2}$. Both CEs together sum up in total CE to $92 \%$ to $97 \%$. The polarization for $\mathrm{Ag}$ starts at around $-0.91 \mathrm{~V}$ vs RHE, exhibiting a $200 \mathrm{mV}$ lower overpotential compared to the blank electrode reduction. The polarization plot shows exponential like behavior: An increase from $-10 \mathrm{~mA} \mathrm{~cm}^{-2}$ to $-100 \mathrm{~mA} \mathrm{~cm}^{-2}$ is facilitated by a potential difference of only $100 \mathrm{mV}$. This behavior clearly shows the nanoparticle benefit in terms of kinetic overpotential. The application of nanoparticles can reduce $\eta_{\mathrm{rt}, \mathrm{C}}$ and decrease or even suppress corrosion phenomena.

\section{5. $\mathrm{CO}_{2}$ reduction with Fumion-bonded GDEs (setup d))}

In Figures $7 \mathrm{e}$ and $7 \mathrm{f}$ the polarization plot and $\mathrm{CE}$ for the $\mathrm{Cu} \mathrm{GDE}$, fed with gaseous $\mathrm{CO}_{2}$ from the backside, is shown. The potential for the lowest $\mathrm{CD}$ is $-0.65 \mathrm{~V} v \mathrm{RHE}$ and decreases to $-0.85 \mathrm{~V}$ vs RHE for the highest CD. The polarization for the Ag GDE 
again shows a slightly higher onset potential of around $-0.72 \mathrm{~V}$ vs RHE and decreases very similarly to $-1.07 \mathrm{~V}$ vs RHE for $-100 \mathrm{~mA} \mathrm{~cm}^{-2}$. The difference of approximately $200 \mathrm{mV}$ for $\mathrm{Ag}$ compared to $\mathrm{Cu}$ reduction experiments is visible for $\mathrm{CDs}$ higher than $-50 \mathrm{~mA} \mathrm{~cm}^{-2}$. The $\mathrm{CE}$ of $\mathrm{Ag}$ and $\mathrm{Cu}$ electrodes for $\mathrm{CO}_{2}$ reduction increases significantly when the GDE is fed with gaseous $\mathrm{CO}_{2}$ from the backside. For $\mathrm{Ag}$ the $\mathrm{CE}$ of $\mathrm{CO}$ is close to $100 \%$ up to $-50 \mathrm{~mA} \mathrm{~cm}^{-2}$ and then drastically decreases to $49 \%$ at $-100 \mathrm{~mA} \mathrm{~cm}^{-2}$. As before, $\mathrm{H}_{2}$ is the only side product. The sum of the CEs for Ag is in the range of $92 \%$ to $97 \%$. The sum of $\mathrm{CE}$ for the $\mathrm{Cu} \mathrm{CO}_{2}$ reduction increases from $73 \%$ to $104 \%$ from the lowest to the highest $\mathrm{CD}$. As in set-up c) $\mathrm{HCOOH}$ is assumed to consume a large part of the electrons at lower CDs. The CE for $\mathrm{Cu} \mathrm{CO}$ formation is around $46 \%$ for $-10 \mathrm{~mA} \mathrm{~cm}^{-2}$ and increases to $65 \%$ for $-30 \mathrm{~mA} \mathrm{~cm}^{-2}$ to decrease again to $41 \%$ for $-100 \mathrm{~mA} \mathrm{~cm}^{-2}$. The $\mathrm{CE}$ for $\mathrm{H}_{2}$ is in the range of $7 \%$ to $20 \%$ while it shows a slight valley where CO reveals its maximum. Nevertheless, no significant increase in HER is visible. Again, with increasing electrode potential the $\mathrm{CE}$ for $\mathrm{C}_{2} \mathrm{H}_{4}$ increases and does not show signs of a maximum, indicating a strong potential dependence for its formation. A pH dependence might also be a possible influencing factor as the mass transport of $\mathrm{H}^{+}$from the bulk to the electrode electrolyte interface probably leads to a shift in $\mathrm{pH}$ [39]. The gas supply to the backside of the GDE mitigates mass transport limitations out of the saturated bulk to the interface of electrode and electrolyte. By using a three phase boundary $\mathrm{CO}_{2}$ only has to be dissolved in the electrolyte and further has to diffuse through a thin aqueous layer to the catalytic active center. It is worthwile to note that the dissolution of $\mathrm{CO}_{2}$ is inevitable as only the dissolved $\mathrm{CO}_{2}$ is electrochemically active $[40,41,42]$. There is no reduction of gaseous $\mathrm{CO}_{2}$ in the GDE. By using the advantages of the three phase boundary $\mathrm{CO}_{2}$ reduction products can still be generated at high CDs of $-100 \mathrm{~mA} \mathrm{~cm}^{-2}$ while suppressing HER. 


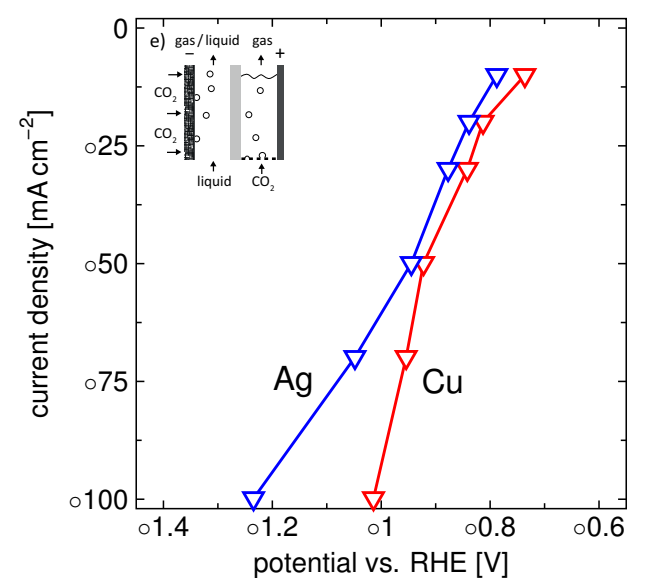

(a) Polarization for setup e) for Nafion-bonded GDEs

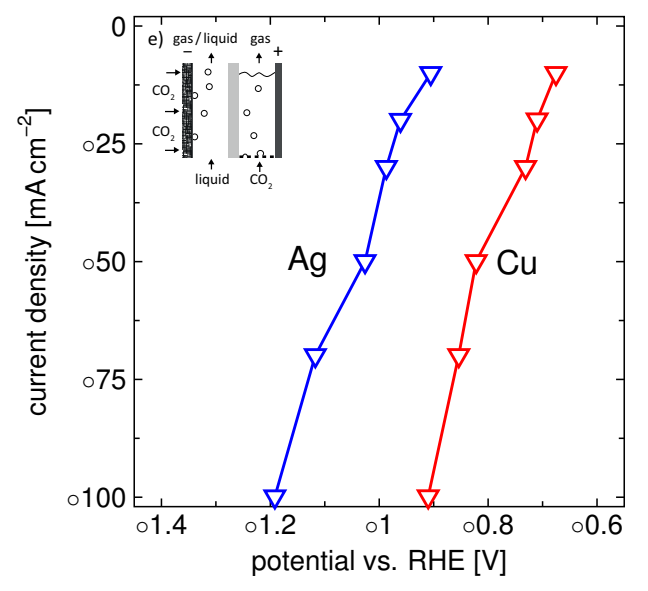

(c) Polarization for setup e) for PTFE-bonded GDEs

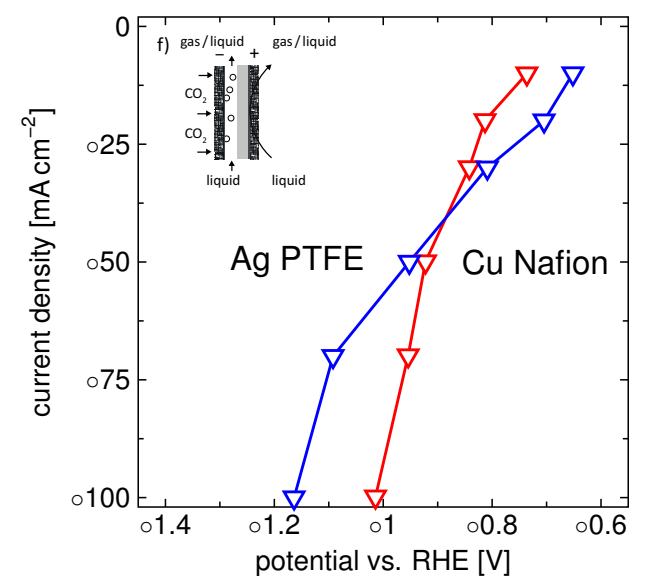

(e) Polarization for setup f) for the Ag PTFEbonded and the $\mathrm{Cu}$ Nafion-bonded GDE

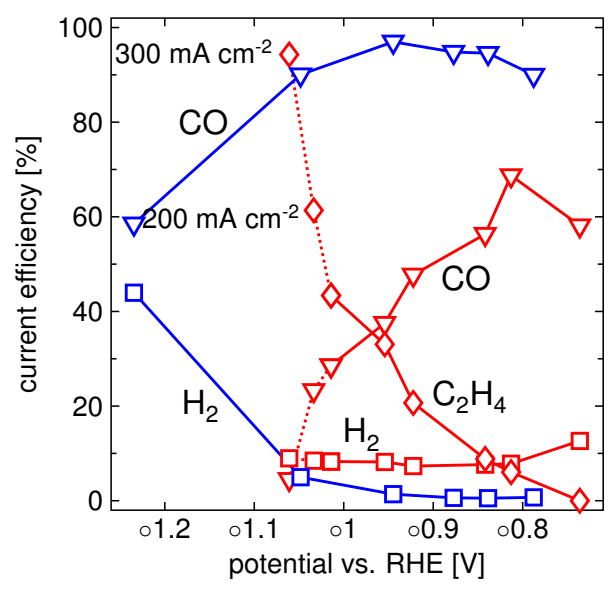

(b) Current efficiency for Nafion-bonded GDEs

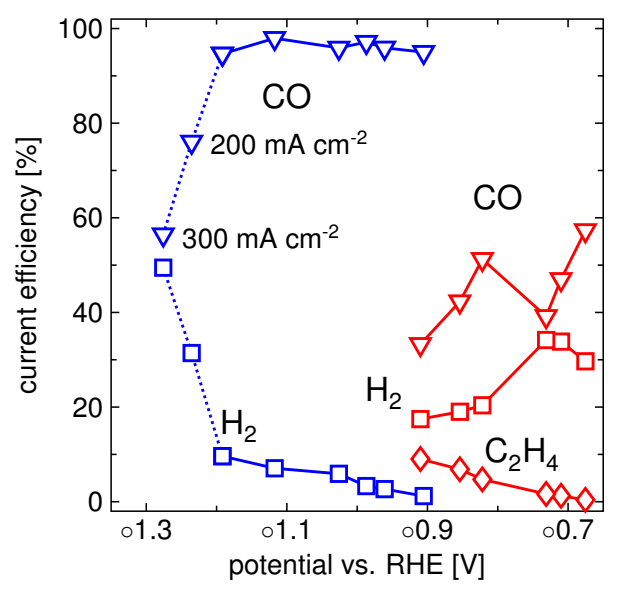

(d) Current efficiency for PTFE-bonded GDEs

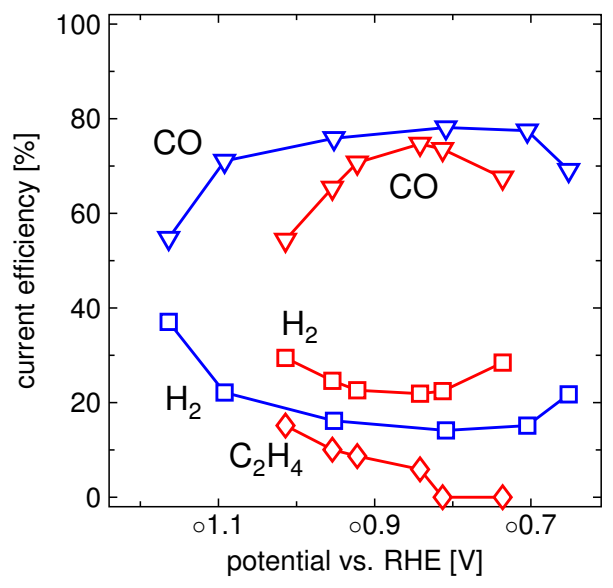

(f) Current efficiency for the Ag PTFE-bonded and the $\mathrm{Cu}$ Nafion-bonded GDE

Figure 8: Polarization plots for set-up e) and set-up f). Current efficiencies for Nafion-bonded GDEs (set-up d)), PTFE-bonded GDEs (set-up e)) and PTFE- as well as Nafion-bonded GDEs (set-up f)) are given. 
3.6. $\mathrm{CO}_{2}$ reduction with Fumion-bonded GDEs with continuous catholyte recirculation (set-up e))

The benefit of a continuous electrolyte can be summarized by a) enhanced and defined electrolyte movement which allows minimization of concentration polarization by usage of static mixers [43], b) defined product removal (especially if liquid phase products have to be considered) and c) easy temperature control (especially if the gab is made very small and thus no easy integration of heat-exchanger is possible).

The onset potential for $\mathrm{Cu} \mathrm{CO}_{2}$ reduction is comparable to set-up c) and d) with $-0.74 \mathrm{~V}$ vs RHE for $\mathrm{Cu}$ and $-0.79 \mathrm{~V}$ vs RHE for $\mathrm{Ag}$, see Figures $8 \mathrm{a}$ and $8 \mathrm{~b}$. The polarization behavior of $\mathrm{Cu}$ and $\mathrm{Ag}$ is very similar up to $-50 \mathrm{~mA} \mathrm{~cm}^{-2}$. For higher CDs the electrode potentials of $\mathrm{Ag}$ increase significantly which might be related to mass transport limitations (as will be discussed later) while $\mathrm{Cu}$ increases more exponential like. The electrode potentials at $-100 \mathrm{~mA} \mathrm{~cm}^{-2}$ are higher for $\mathrm{Ag}$ and $\mathrm{Cu}$ compared to set-up d). This is probably a result of the controlled temperature. Especially for the higher CDs the temperature in set-up d) increases drastically, whereas in set-up e) the temperature is controlled to $30^{\circ} \mathrm{C}$ by an external heat exchanger. The higher temperatures lead to lower overpotentials. $\left|\eta_{\mathrm{rt}, \mathrm{c}}\right|$ decreases as the exchange current density increases with Arrhenius like behavior. Further, $\eta_{c, C}$ decreases as a result of enhanced particle movement but should not be visible in the presented data as the data is IR-drop compensated individually for each applied CD. The increase in temperature for the batch mode experiment over time for one working point also influences the $\mathrm{CE}$, which can be seen in the individual GC analysis. With increasing time the concentration of $\mathrm{CO}_{2}$ reduction products decreases in set-up d) whereas for $\mathrm{H}_{2}$ increases. This is probably a result of the lower $\mathrm{CO}_{2}$ solubility at higher temperatures [27]. This trend is not visible for the continuous recirculation of electrolyte. For $\mathrm{Ag} \mathrm{CO}_{2}$ reduction the $\mathrm{CE}$ for $\mathrm{CO}$ is close to $100 \%$ up to $-50 \mathrm{~mA} \mathrm{~cm}^{-2}$ and then decreases to $58 \%$ compared to $51 \%$ for set-up d).

The CO CEs for the $\mathrm{Cu}$ GDE in set-up e) are slightly higher compared to the tem- 
perature uncontrolled system but also show this typical peak like behavior. At the same time, the $\mathrm{CE}$ for $\mathrm{H}_{2}$ is lower. It is in the range of $8 \%-12 \%$, whereas the increase in $\mathrm{C}_{2} \mathrm{H}_{4}$ is stronger and ends at $43 \%$ for $-100 \mathrm{~mA} \mathrm{~cm}^{-2}$. Additionally to the polarization up to $-100 \mathrm{~mA} \mathrm{~cm}^{-2}$, higher CDs were applied to the system to evaluate if the increase in $\mathrm{C}_{2} \mathrm{H}_{4}$ formation will hold at even higher loads. CDs up to $-300 \mathrm{~mA} \mathrm{~cm}^{-2}$ were applied (sum of $\mathrm{CE}$ is $93 \%$ for $-200 \mathrm{~mA} \mathrm{~cm}^{-2}$ and $104 \%$ for $-300 \mathrm{~mA} \mathrm{~cm}^{-2}$ ). Surprisingly, the CEs for $\mathrm{C}_{2} \mathrm{H}_{4}$ increase to $61 \%$ and $94 \%$, respectively (shown by the dashed line in Figure $8 \mathrm{~b}$ ) while the $\mathrm{CE}$ for $\mathrm{CO}$ stays at $4 \%$ and $23 \%$, respectively, and $8 \%$ for $\mathrm{H}_{2}$. Whether the increase in $\mathrm{CE}$ for $\mathrm{C}_{2} \mathrm{H}_{4}$ is a result of the controlled temperature or the slightly different electrolyte $\mathrm{pH}$ is not completely clear, since $\mathrm{C}_{2} \mathrm{H}_{4}$ shows $\mathrm{pH}$ dependence on $\mathrm{Cu}(100)$ $[44,45]$. In the continuous recirculation mode the $\mathrm{pH}$ for the catholyte is slightly lower compared to batch mode (see SI). Nevertheless, no mass transport limitations can be seen up to $-300 \mathrm{~mA} \mathrm{~cm}^{-2}$. This clearly shows the ability of using such an electrode for high rate $\mathrm{C}_{2} \mathrm{H}_{4}$ production. Another reason for the good performance may be the ability of $\mathrm{Cu}$ to form $\mathrm{C}_{2} \mathrm{H}_{4}$ (12 electron transfer for two necessary $\mathrm{CO}_{2}$ ) in the case of $\mathrm{CO}_{2}$ mass transport limitation. At $\mathrm{Ag}$ (two electron transfer for one necessary $\mathrm{CO}_{2}$ ) this is not possible and thus, only $\mathrm{H}_{2}$ formation is possible if not enough gaseous educt is available. Additionally, the effect of catalyst and polymeric binder interaction may play a key role here.

3.7. $\mathrm{CO}_{2}$ reduction with PTFE-bonded GDEs with continuous catholyte recirculation (set-up e))

If Nafion as the polymeric binder is replaced by PTFE, the polarization and CE plots for the Ag GDE show improved performance as depicted in Figures 8c and 8d. The onset potential increases about $100 \mathrm{mV}$ compared to the Nafion-bonded GDE, but a slightly lower electrode potential is needed for the highest CD. The Cu GDE shows similar trends, whereas the potential for the highest CD is $100 \mathrm{mV}$ lower compared to the Nafion-bonded GDE.

The overall very high $\mathrm{CE}$ of the $\mathrm{Ag} \mathrm{GDE}$ is remarkable. The $\mathrm{CE}$ for $\mathrm{CO}$ is higher 
than $90 \%$ for all applied CDs. A slight increase in HER can be noticed for the higher CDs. Additionally, the CEs for experiments with $-200 \mathrm{~mA} \mathrm{~cm}^{-2}$ and $-300 \mathrm{~mA} \mathrm{~cm}^{-2}$ are plotted with the dashed line. CEs over $50 \%$ are possible for CDs up to $-300 \mathrm{~mA} \mathrm{~cm}^{-2}$. The $\mathrm{H}_{2} \mathrm{CE}$ for the $\mathrm{Cu}$ GDE is in the range of $17 \%-35 \%$ and thus higher compared to the Nafion-bonded GDE while the CE for CO shows slightly lower absolute values but a very similar course. The steep increase in $\mathrm{C}_{2} \mathrm{H}_{4}$ formation at higher potentials cannot be reproduced compared to the Nafion-bonded GDE. Again, the total CE does not sum up

to $100 \%$, but interestingly a decrease in the total CE for increasing CDs can be observed (from lowest to highest CD: $87.4 \%, 82.1 \%, 75.0 \%, 76.3 \%, 68.2 \%$ and $59.8 \%$ ). This is very untypical compared to the course of $\mathrm{CE}$ for the other $\mathrm{Cu}$ GDEs. Perhaps this phenomenon can be related to GDE fabrication challenges. Using the small $\mathrm{Cu}$ nanoparticles made it difficult to produce and especially press the electrode. Often cracks hinder even $\mathrm{CO}_{2}$ distribution and thus hamper proper set-up of the three phase boundary. High rate $\mathrm{CO}_{2}$ reduction via a GDE with PTFE as polymeric binder has been shown elsewhere [7].

\subsection{Towards an energetic efficient reactor (set-up f))}

A CCM at the anode mitigates ohmic drops within the anolyte and thus results in better EE, as can be see in Figure 5. Consequently, the catholyte electrolyte gap should be as thin as possible to alleviate ohmic losses. The electrolyte gap is diminished from $20 \mathrm{~mm}$ (set-up e)) to $0.5 \mathrm{~mm}$ in this set-up. Following, the hydrodynamics of the system change. Accordingly, in a first step system $\mathrm{f}$ ) is characterized without current under various $\mathrm{CO}_{2}$ flow rates. In Figure 9 the pressure loss over the GDE and the pressure loss along the buffer channel length are depicted. The pressure loss over the GDE increases with increasing $\mathrm{CO}_{2}$ volume flow rate. The pressure loss along the channel length shows first an increasing and then a decreasing course. As the insertion of gaseous $\mathrm{CO}_{2}$ leads to an increase in total volume flow, one would rather expect a continuous increase in pressure loss. There are two possible reasons for our observations. First, swelling of the membrane by the uptake of water 


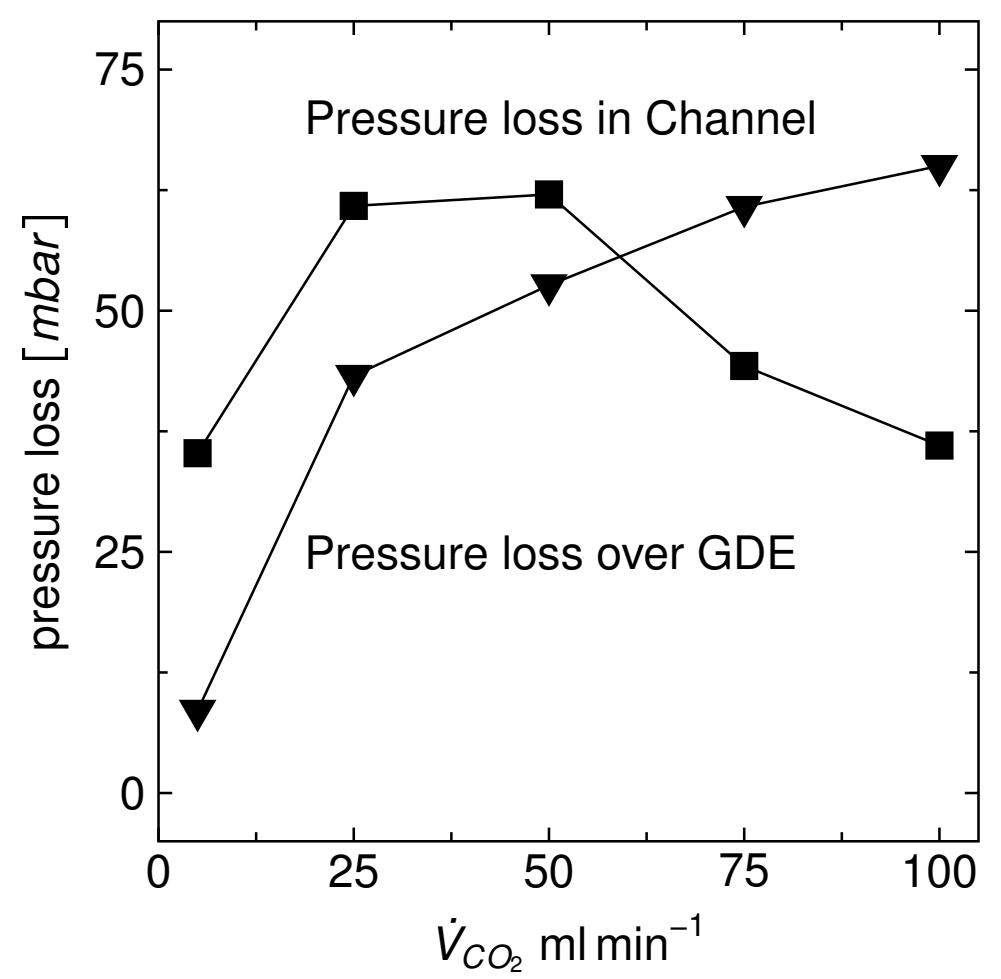

Figure 9: Pressure loss over the GDE and along the channel length are plotted over the $\mathrm{CO}_{2}$ flow rate for set-up f).

results in a partial channel obstruction and thus diminishes the hydraulic diameter. The membrane wrinkles into the cavities of the spacer to block the channel. Second, the removal of air bubbles from the spacer-GDE interface might be more difficult at higher gas flow rates. If surface properties of spacer, gas and electrolyte are not chosen right, gas bubbles can be trapped in the spacer. The increase in total volume and by this the increase in total pressure might counteract these challenges. If the pressure inside the catholyte compartment is increased compared to the anode compartment, the swollen membrane is pressed against the porous titanium sinter plate of the anode and the catholyte channel is forced open. Thus, the hydraulic diameter is fixed to the channel width and allows better gas bubble removal and electrolyte flow. An indication for that behavior is the non-linear characteristic of the pressure loss over the GDE. At increasing pressure, the volume flow controlled by the mass flow controller decreases. Thus, the $100 \mathrm{sccm}$ might only be $90 \mathrm{ml} \mathrm{min}^{-1}$ under the elevated pressure. 
The Ag onset potential for the lowest CD is significantly smaller compared to the twosided buffered system, whereas the necessary electrode potential for $-100 \mathrm{~mA} \mathrm{~cm}^{-2}$ is nearly the same around $-1.16 \mathrm{~V}$ vs RHE, see Figure 8e. The reason for this different polarization is not completely clear. Ongoing work showed that the performance of the anode in setup f) is difficult to handle. This not completely reproducible anodic polarization results probably in an difficult IR drop compensation. Perhaps the EIS measurement is affected by the unhomogeneous electric field and results incorrect data. The polarization of $\mathrm{Cu}$ is nearly unaffected by the change in set-up compared to set-up e). Avoiding the mentioned ohmic drops results in a decrease of cell potential from $4 \mathrm{~V}$ to $2.4 \mathrm{~V}$ for the lowest $\mathrm{CD}$ and from 8.2 $\mathrm{V}$ to $3.2 \mathrm{~V}$ for the highest $\mathrm{CD}$, see Figure 5.

A drawback of the small buffer layer thickness of the catholyte is the resulting high pressure drop along the buffer channel length. To understand how hydrodynamics influence the electrochemical $\mathrm{CO}_{2}$ reduction, a schematic sketch for the pressure profiles in the catholyte is shown in Figure 10. The black line shows a typical pressure profile along the catholyte channel. At the channel inlet the pressure is higher than at the outlet due to friction. As the pressure on the gas side can be assumed constant without any gradient, the pressure difference across the GDE will vary between the entry and the exit of the cell. As a consequence, the location of the three phase boundary varies over the length of the channel. If hydrodynamics are chosen correctly, the three phase boundary will be inside the catalyst layer of the GDE, see white dotted line in Figure 10. If the pressure gradient is too high, to much electrolyte penetration into the GDE or even a liquid breakthrough may deactivate the three phase boundary of the GDE to a certain extent which is indicated by the red dotted line in Figure 10. This drawback results in a inferior CE for CO compared to the two-sided buffered system. At the places with a liquid breakthrough no supply with $\mathrm{CO}_{2}$ to the three phase boundary is possible, moving the system performance in the direction of set-up c). The GDE in the energetically most promising set-up is deactivated and HER increases. CEs for $\mathrm{Ag} \mathrm{CO}_{2}$ reduction of roughly $60 \%-80 \%$ indicate a deteriorated performance compared 


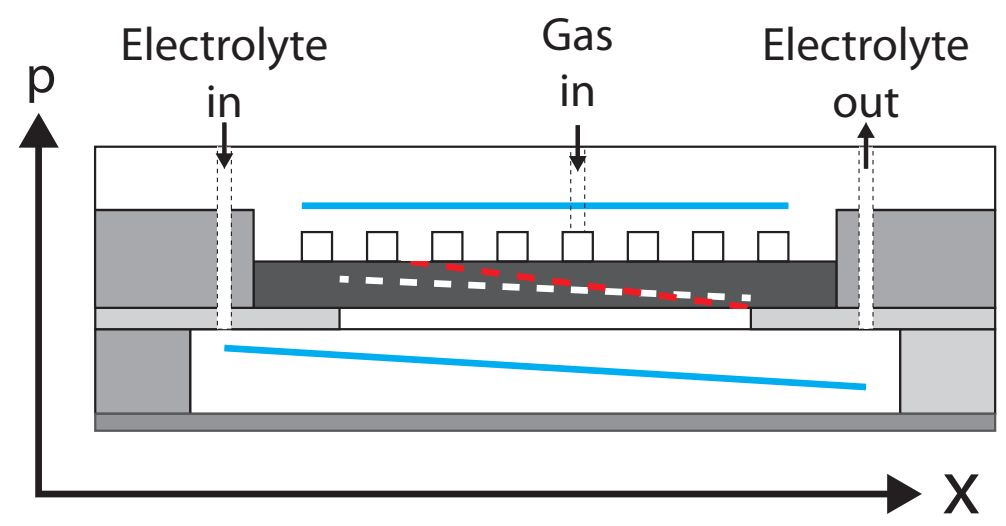

Figure 10: Pressure profiles within the ecMR. The blue lines indicate the pressure profile within the cathodic buffer channel (lower line) and the constant pressure of $\mathrm{CO}_{2}$ in the serpentine flow field (upper line). A different static pressure of the electrolyte results in a different place of the three phase boundary inside the GDE (white-dotted line). If the pressure loss along the buffer channel exceeds a certain maximum a liquid breakthrough might result. This leads to a partial deactivation of the GDE and a shift of the three-phase boundary (red dotted line), which impairs the performance of the GDE.

to set-up e), although the PTFE-bonded and pressed Ag GDE was used. A very similar behavior is visible for the $\mathrm{Cu}$ Fumion-bonded GDE. The $\mathrm{CE}$ for $\mathrm{H}_{2}$ is in the range of 20-30\% and thus higher as in set-up e). As before, deactivation of parts of the GDE is the most likely explanation for this behavior.

Another interesting observation made in our ongoing work is a decreasing anode performance if higher CDs than $100 \mathrm{~mA} \mathrm{~cm}^{-2}$ are applied. This decreasing performance can be explained by an increasing oxygen evolution at the catalyst layer. This results in a lift-off of the CCM and thus a loss of electrical contact of the catalyst. Cross-influences of the $\mathrm{CO}_{2}$ insertion strategy and the resulting higher total pressure of the catholyte compared to the anolyte have to be considered here. A trans-membrane pressure can guarantee a defined contact of the CCM to the porous sinter plate and additionally leads to higher $\mathrm{CO}_{2}$ concentrations in the electrolyte according to Henrys law.

\section{Conclusion}

\section{Statements on cell design}

An exchange of the cathode catalyst of a PEM water electrolyser with a catalyst that is 
active for $\mathrm{CO}_{2}$ reduction theoretically makes the zero gap assembly the perfect candidate for co-electrolysis. The absence of liquid anolyte and catholyte mitigates ohmic losses, which are merely constituted by the thin solid electrolyte, would allow a highly energetic reduction. Unfortunately, the acidic environment inside or next to the cation exchange membrane results in an almost exclusive hydrogen production. On the contrary, a two-sided buffered system with high ohmic losses yields high rate and easy to control $\mathrm{CO}_{2}$ reduction to $\mathrm{CO}$ and $\mathrm{C}_{2} \mathrm{H}_{4}$ with a low energetic efficiency. Thus, this system is the perfect candidate for comparing different gas diffusion electrodes where the energetic efficiency is of minor importance. A one-sided buffered set-up is the energetically most promising set-up for the co-electrolysis of $\mathrm{CO}_{2}$. A catalyst coated membrane as the anode mitigates any ohmic losses in the anolyte and a buffer layer between cathode and membrane allows for $\mathrm{pH}$ control and thus $\mathrm{CO}_{2}$ reduction. In a cation exchange membrane based ecMR with a catalyst coated membrane as anode a $\mathrm{pH}$ difference between anolyte and catholyte is necessary for $\mathrm{CO}_{2}$ reduction. This leads to a thermodynamically-based increase in minimal "thermoneutral" cell potential. Further considerations are necessary to circumvent energy losses due to $\mathrm{pH}$ deviations between anode and cathode to increase the energetic efficiency.

\section{Statements on process control for a one-sided buffered set-up}

Using a cathode buffer layer thickness of only $0.5 \mathrm{~mm}$ results in high energetic efficiencies, but increases the complexity of process control, especially hydrodynamics. Additionally, the permanent contact of the catalyst coated membrane to the current collector at the anode especially at high CD is a challenge. The catalyst coated membrane tends to lift off as a result of the increased gas evolution. Then, the catalyst is no longer active and the energetic efficiency deteriorates. A very dense spacer in the buffer layer would allow the static fixation of the membrane. On the other hand, a dense spacer results in a lower porosity and thus results in lower ionic conductivity and higher pressure drops along the channel length. High pressure drops along the channel length lead to inhomogeneous three phase boundaries and 
inferior current efficiency. Here, further research is needed to exploit the full performance of the gas diffusion electrode in a one-sided buffered system.

\section{Statements on GDE production}

A nanoparticulate silver electrode with a $\mathrm{CO}_{2}$ supply from the backside allows $\mathrm{SG}$ production up to $300 \mathrm{~mA} \mathrm{~cm}^{-2}$ (1:1 CO: $\left.\mathrm{H}_{2}\right)$ at $30^{\circ} \mathrm{C}$ and 1 bar $\mathrm{CO}_{2}$ partial pressure. With the same boundary conditions, $\mathrm{CDs}$ for $\mathrm{C}_{2} \mathrm{H}_{4}$ formation with a $\mathrm{CE}$ higher than $90 \%$ with copper based GDEs are possible up to $300 \mathrm{~mA} \mathrm{~cm}^{-2}$. In general, the different product compositions resulting from different potentials can be used in different applications: the mixture at lower CDs of $\mathrm{CO}: \mathrm{H}_{2}: \mathrm{C}_{2} \mathrm{H}_{4}$ is interesting in hydroformulation chemistry e.g. for the production of propionic acid. Our research shows that GDEs are imperative to achieve high CDs compared to $\mathrm{CO}_{2}$ saturated electrolytes. The presented results show that not only the catalyst determines the performance of a GDE. Beyond the catalyst the choice of polymeric binder (whether hydrophilic or hydrophobic), as well as production method, temperature control and the right hydrodynamics highly influence the performance of a GDE. Further research with regard to a stable hydrodynamics and process control are indispensable. Additionally, the electrolyte system and interfacial phenomena at high current densities have to be considered.

\section{Acknowledgements}

M. W. acknowledges the support through an Alexander-von-Humboldt Professorship. R.S. and J.-B. V. are supported by the Cluster of Excellence Tailor-Made Fuels from Biomass, which is funded by the Excellence Initiative by the German Federal and State Governments to promote science and research at German universities. Additional support through the Projecthouse Power-to-Fuels, P2F at RWTH Aachen and JARA Energy is gratefully acknowledged. The authors thank Laura Keller for proofreading and valuable suggestions. Karl-Heinz Stollenwerk is acknowledged for sharing his experience and supporting us with GC measurements. 


\section{References}

\section{References}

[1] G. A. Olah, A. Goeppert, G. S. Prakash, Beyond oil and gas: the methanol economy, John Wiley \& Sons, 2011.

[2] E. V. Kondratenko, G. Mul, J. Baltrusaitis, G. O. Larrazabal, J. Perez-Ramirez, Status and perspectives of $\mathrm{CO}_{2}$ conversion into fuels and chemicals by catalytic, photocatalytic and electrocatalytic processes, Energy \& environmental science 6 (11) (2013) 3112-3135.

[3] J.-P. Jones, G. Prakash, G. A. Olah, Electrochemical $\mathrm{CO}_{2}$ reduction: recent advances and current trends, Israel Journal of Chemistry 54 (10) (2014) 1451-1466.

[4] G. A. Olah, G. S. Prakash, A. Goeppert, Anthropogenic chemical carbon cycle for a sustainable future, Journal of the American Chemical Society 133 (33) (2011) 1288112898.

[5] P. Kaiser, R. B. Unde, C. Kern, A. Jess, Production of liquid hydrocarbons with $\mathrm{CO}_{2}$ as carbon source based on reverse water-gas shift and fischer-tropsch synthesis, Chemie Ingenieur Technik 85 (4) (2013) 489-499.

[6] A. Goeppert, M. Czaun, J.-P. Jones, G. S. Prakash, G. A. Olah, Recycling of carbon dioxide to methanol and derived products-closing the loop, Chemical Society Reviews 43 (23) (2014) 7995-8048.

[7] R. L. Cook, R. C. MacDuff, A. F. Sammells, High rate gas phase $\mathrm{CO}_{2}$ reduction to ethylene and methane using gas diffusion electrodes, Journal of the Electrochemical Society 137 (2) (1990) 607-608.

[8] K. Manthiram, B. J. Beberwyck, A. P. Alivisatos, Enhanced electrochemical methanation of carbon dioxide with a dispersible nanoscale copper catalyst, Journal of the American Chemical Society 136 (38) (2014) 13319-13325.

[9] D. Ren, Y. Deng, A. D. Handoko, C. S. Chen, S. Malkhandi, B. S. Yeo, Selective electrochemical reduction of carbon dioxide to ethylene and ethanol on copper(i)oxide catalysts, ACS Catalysis 5 (5) (2015) 2814-2821.

[10] C. Delacourt, P. L. Ridgway, J. B. Kerr, J. Newman, Design of an electrochemical cell making syngas $\left(\mathrm{CO}+\mathrm{H}_{2}\right)$ from $\mathrm{CO}_{2}$ and $\mathrm{H}_{2} \mathrm{O}$ reduction at room temperature, Journal of The Electrochemical Society 155 (1) (2008) B42-B49.

[11] E. J. Dufek, T. E. Lister, M. E. McIlwain, Bench-scale electrochemical system for generation of CO and syn-gas, Journal of Applied Electrochemistry 41 (6) (2011) 623-631.

[12] Y. Hori, H. Wakebe, T. Tsukamoto, O. Koga, Electrocatalytic process of CO selectivity in electrochemical reduction of $\mathrm{CO}_{2}$ at metal electrodes in aqueous media, Electrochimica Acta 39 (11-12) (1994) 1833-1839. 
[13] A. A. Peterson, J. K. Nørskov, Activity descriptors for $\mathrm{CO}_{2}$ electroreduction to methane on transition-metal catalysts, The Journal of Physical Chemistry Letters 3 (2) (2012) $251-258$.

[14] Y. Hori, A. Murata, R. Takahashi, S. Suzuki, Electroreduction of carbon monoxide to methane and ethylene at a copper electrode in aqueous solutions at ambient temperature and pressure, Journal of the American Chemical Society 109 (16) (1987) 5022-5023.

[15] Y. Hori, A. Murata, R. Takahashi, Formation of hydrocarbons in the electrochemical reduction of carbon dioxide at a copper electrode in aqueous solution, Journal of the Chemical Society, Faraday Transactions 1: Physical Chemistry in Condensed Phases 85 (8) (1989) 2309-2326.

[16] D. Ren, J. Fong, B. S. Yeo, The effects of currents and potentials on the selectivities of copper toward carbon dioxide electroreduction, Nature communications 9 (1) (2018) 925.

[17] S. Lin, C. S. Diercks, Y.-B. Zhang, N. Kornienko, E. M. Nichols, Y. Zhao, A. R. Paris, D. Kim, P. Yang, O. M. Yaghi, et al., Covalent organic frameworks comprising cobalt porphyrins for catalytic $\mathrm{CO}_{2}$ reduction in water, Science 349 (6253) (2015) 1208-1213.

[18] Z. Weng, J. Jiang, Y. Wu, Z. Wu, X. Guo, K. L. Materna, W. Liu, V. S. Batista, G. W. Brudvig, H. Wang, Electrochemical $\mathrm{CO}_{2}$ reduction to hydrocarbons on a heterogeneous molecular Cu catalyst in aqueous solution, J. Am. Chem. Soc 138 (26) (2016) 8076-8079.

[19] I. Merino-Garcia, E. Alvarez-Guerra, J. Albo, A. Irabien, Electrochemical membrane reactors for the utilisation of carbon dioxide, Chemical Engineering Journal 305 (2016) $104-120$.

[20] B. Endrődi, G. Bencsik, F. Darvas, R. Jones, K. Rajeshwar, C. Janáky, Continuousflow electroreduction of carbon dioxide, Progress in Energy and Combustion Science 62 (2017) 133-154.

[21] M. Carmo, D. L. Fritz, J. Mergel, D. Stolten, A comprehensive review on pem water electrolysis, International journal of hydrogen energy 38 (12) (2013) 4901-4934.

[22] E. Brightman, J. Dodwell, N. van Dijk, G. Hinds, In situ characterisation of pem water electrolysers using a novel reference electrode, Electrochemistry Communications 52 (2015) 1-4.

[23] S. Adler, B. Henderson, M. Wilson, D. Taylor, R. Richards, Reference electrode placement and seals in electrochemical oxygen generators, Solid State Ionics 134 (1-2) (2000) $35-42$.

[24] T. Reier, M. Oezaslan, P. Strasser, Electrocatalytic oxygen evolution reaction (oer) on $\mathrm{Ru}$, Ir, and Pt catalysts: a comparative study of nanoparticles and bulk materials, Acs Catalysis 2 (8) (2012) 1765-1772. 
[25] H. Yano, F. Shirai, M. Nakayama, K. Ogura, Electrochemical reduction of $\mathrm{CO}_{2}$ at threephase (gas | liquid | solid) and two-phase (liquid | solid) interfaces on Ag electrodes, Journal of Electroanalytical Chemistry 533 (1) (2002) 113-118.

[26] E. E. Benn, B. Gaskey, J. D. Erlebacher, Suppression of hydrogen evolution by oxygen reduction in nanoporous electrocatalysts, Journal of the American Chemical Society 139 (10) (2017) 3663-3668.

[27] J. Carroll, J. Slupsky, A. Mather, The solubility of carbon dioxide in water at low pressure, Journal of Physical and Chemical Reference Data 20 (6).

[28] K. Jiao, X. Li, Water transport in polymer electrolyte membrane fuel cells, Progress in Energy and Combustion Science 37 (3) (2011) 221-291.

[29] S. Komatsu, M. Tanaka, A. Okumura, A. Kungi, Preparation of Cu-solid polymer electrolyte composite electrodes and application to gas-phase electrochemical reduction of $\mathrm{CO}_{2}$, Electrochimica acta 40 (6) (1995) 745-753.

[30] G. S. Prakash, F. A. Viva, G. A. Olah, Electrochemical reduction of $\mathrm{CO}_{2}$ over Snnafion $\AA$ coated electrode for a fuel-cell-like device, Journal of Power Sources 223 (2013) 68-73.

[31] L. Aeshala, S. Rahman, A. Verma, Effect of solid polymer electrolyte on electrochemical reduction of $\mathrm{CO}_{2}$, Separation and purification technology 94 (2012) 131-137.

[32] Y. Hori, H. Ito, K. Okano, K. Nagasu, S. Sato, Silver-coated ion exchange membrane electrode applied to electrochemical reduction of carbon dioxide, Electrochimica Acta 48 (18) (2003) 2651-2657.

[33] K. P. Kuhl, E. R. Cave, D. N. Abram, T. F. Jaramillo, New insights into the electrochemical reduction of carbon dioxide on metallic copper surfaces, Energy \& Environmental Science 5 (5) (2012) 7050-7059.

[34] D. W. DeWulf, T. Jin, A. J. Bard, Electrochemical and surface studies of carbon dioxide reduction to methane and ethylene at copper electrodes in aqueous solutions, Journal of the Electrochemical Society 136 (6) (1989) 1686-1691.

[35] C. Reller, R. Krause, E. Volkova, B. Schmid, S. Neubauer, A. Rucki, M. Schuster, G. Schmid, Selective electroreduction of $\mathrm{CO}_{2}$ toward ethylene on nano dendritic copper catalysts at high current density, Advanced Energy Materials 7 (12).

[36] K. P. Kuhl, T. Hatsukade, E. R. Cave, D. N. Abram, J. Kibsgaard, T. F. Jaramillo, Electrocatalytic conversion of carbon dioxide to methane and methanol on transition metal surfaces, Journal of the American Chemical Society 136 (40) (2014) 14107-14113.

[37] A. J. Martin, G. O. Larrazabal, J. Perez-Ramirez, Towards sustainable fuels and chemicals through the electrochemical reduction of $\mathrm{CO}_{2}$ : lessons from water electrolysis, Green Chemistry 17 (12) (2015) 5114-5130. 
[38] C. W. Li, M. W. Kanan, $\mathrm{CO}_{2}$ reduction at low overpotential on $\mathrm{Cu}$ electrodes resulting from the reduction of thick $\mathrm{Cu}_{2} \mathrm{O}$ films, Journal of the American Chemical Society 134 (17) (2012) 7231-7234.

[39] C. Delacourt, P. L. Ridgway, J. Newman, Mathematical modeling of $\mathrm{CO}_{2}$ reduction to $\mathrm{CO}$ in aqueous electrolytes i. kinetic study on planar silver and gold electrodes, Journal of The Electrochemical Society 157 (12) (2010) B1902-B1910.

[40] Y. Hori, Electrochemical $\mathrm{CO}_{2}$ reduction on metal electrodes, in: Modern aspects of electrochemistry, Springer, 2008, pp. 89-189.

[41] T. E. Teeter, P. Van Rysselberghe, Reduction of carbon dioxide on mercury cathodes, The Journal of Chemical Physics 22 (4) (1954) 759-760.

[42] W. Paik, T. Andersen, H. Eyring, Kinetic studies of the electrolytic reduction of carbon dioxide on the mercury electrode, Electrochimica Acta 14 (12) (1969) 1217-1232.

[43] T. Ralph, M. Hitchman, J. Millington, F. Walsh, Mass transport in an electrochemical laboratory filterpress reactor and its enhancement by turbulence promoters, Journal of The Electrochemical Society 41 (4) (1996) 591-603.

[44] K. J. P. Schouten, E. P. Gallent, M. T. Koper, The influence of ph on the reduction of CO and $\mathrm{CO}_{2}$ to hydrocarbons on copper electrodes, Journal of Electroanalytical Chemistry 716 (2014) 53-57.

[45] R. Kas, R. Kortlever, H. Yılmaz, M. Koper, G. Mul, Manipulating the hydrocarbon selectivity of copper nanoparticles in $\mathrm{CO}_{2}$ electroreduction by process conditions, ChemElectroChem 2 (3) (2015) 354-358.

\section{Supplementary Material}

Design aspects of ecMRs for $\mathrm{CO}_{2}$ reduction

Current density $(C D)$

The current density (CD) is the surface normalized current of the electrochemical membrane reactor. The $\mathrm{CD}$ can be correlated to the production rate by the derivation of Faraday's law

$$
i^{\prime \prime}=\dot{n}^{\prime \prime} \cdot z \cdot F
$$

where $\dot{\mathrm{i}}$ is the current density, $\dot{\mathrm{n}}$ " the production rate, $z$ the charge transfer number and $F$ the Faraday's constant. Equation 5 is only valid if all electrons are consumed in the desired reaction.

Current Efficiency (CE)

The CE accounts for the share of current driving the desired reaction to the overall current. 
Table S1: List of abbreviations in SI

\begin{tabular}{l|l|l} 
Abbreviation & Full Name & Unit \\
\hline \hline $\mathrm{Ag}$ & silver & {$[-]$} \\
$\mathrm{C}_{2} \mathrm{H}_{4}$ & ethylene & {$[-]$} \\
$\mathrm{C}_{2} \mathrm{H}_{6}$ & ethane & {$[-]$} \\
$\mathrm{CCM}$ & catalyst coated membrane & {$[-]$} \\
$\mathrm{CD}$ & current density & {$\left[\mathrm{mA} \mathrm{cm}{ }^{-2}\right]$} \\
$\mathrm{CE}$ & current efficiency & {$[\%]$} \\
$\mathrm{CEM}$ & cation exchange membrane & {$[-]$} \\
$\mathrm{CO}$ & carbon monoxide & {$[-]$} \\
$\mathrm{CO}$ & carbon dioxide & {$[-]$} \\
$\mathrm{Cu}$ & copper & {$[-]$} \\
$\mathrm{EE}$ & energetic efficiency & {$[\%]$} \\
$\mathrm{GC} / \mathrm{MS}$ & gas chromatography - mass spectrometry & {$[-]$} \\
$\mathrm{GDE}$ & gas diffusion electrode & {$[-]$} \\
$\mathrm{GDL}$ & gas diffusion layer & {$[-]$} \\
$\mathrm{H}_{2}$ & hydrogen & {$[-]$} \\
$\mathrm{HCl}$ & hydrochloric acid & {$[-]$} \\
$\mathrm{IrO}$ & iridium oxide & {$[-]$} \\
$\mathrm{O}_{2}$ & oxygen & {$[-]$} \\
$\mathrm{OER}$ & oxygen evolution reaction & {$[-]$} \\
$\mathrm{PEM}$ & polymer electrolyte membrane & {$[-]$} \\
$\mathrm{SG}$ & synthesis gas & {$[-]$} \\
$\mathrm{TCD}$ & thermal conductivity sensor & {$[-]$} \\
\hline
\end{tabular}


Table S2: List of symbols in SI

\begin{tabular}{l|l|l} 
Symbol & Full Name & Unit \\
\hline \hline$\Delta_{\mathrm{r}} \mathrm{H}_{\mathrm{i}}^{0}$ & enthalpies of reaction for species i & {$\left[\mathrm{kJ} \mathrm{mol}^{-1}\right]$} \\
$\eta_{\mathrm{CE}, \mathrm{i}}$ & current efficiency for species i & {$[\%]$} \\
$\eta_{\mathrm{EE}}$ & energetic efficiency & {$[\%]$} \\
$\mathrm{E}_{\text {cell }}$ & cell potential & {$[\mathrm{V}]$} \\
$\mathrm{F}$ & Faraday's constant & $96485 \mathrm{~A} \mathrm{~s} \mathrm{~mol}^{-1}$ \\
$\dot{\mathrm{H}}_{\mathrm{i}}$ & enthalpy flow (i: in or out) & {$[\mathrm{J}]$} \\
$\dot{\mathrm{i}}^{\prime \prime}$ & current density & {$\left[\mathrm{mA} \mathrm{cm}{ }^{-2}\right]$} \\
$\mathrm{I}_{\text {cell }}$ & total cell current & {$[\mathrm{A}]$} \\
$\dot{\mathrm{n}}^{\prime \prime}$ & total production rate & {$\left[\mathrm{mol} \mathrm{m}^{-2} \mathrm{~s}^{-1}\right]$} \\
$\dot{\mathrm{n}}_{i}$ & specific production rate for species i & {$\left[\mathrm{mol} \mathrm{m}^{-2} \mathrm{~s}^{-1}\right]$} \\
$\mathrm{z}_{\mathrm{i}}$ & charge transfer number for species i & {$[-]$} \\
$\mathrm{P}_{\mathrm{el}}$ & power input & {$[\mathrm{W}]$} \\
\hline
\end{tabular}

With $\dot{\mathrm{n}}_{i}$ as the specific production rate of product i and Equation 5, the CE can be expressed as

$$
\eta_{C E}=\frac{\dot{n}_{i}^{\prime \prime} \cdot z \cdot F}{i^{\prime \prime}}
$$

For the SG process the CO CE should be in the range from $33 \%$ to $50 \%$, while $\mathrm{H}_{2}$ is formed from the remaining current share $(2: 1 \mathrm{H} / \mathrm{C}$ ratio for methanol process and 1:1 - 3:2 $\mathrm{H} / \mathrm{C}$ ratio for dimethylether process).

Energetic efficiency (EE)

The EE is the ratio of chemically-bonded energy leaving the system to the input of electrical energy. For a continuous ecMR with constant system temperature the EE is

$$
\eta_{E E}=\frac{\dot{H}_{\text {out }}-\dot{H}_{\text {in }}}{P_{\text {el }}}=\frac{\frac{I_{\text {cell }}}{z \cdot F} \cdot \Delta_{r} H^{0}}{E_{\text {cell }} \cdot I_{\text {cell }}}=\frac{\Delta_{r} H^{0}}{E_{\text {cell }} \cdot z \cdot F}
$$

The power or energy input $P$ can be calculated as product of the cell current $\left(I_{\text {cell }}\right)$ and cell potential $\left(E_{\text {cell }}\right)$. The enthalpy leaving the system as gaseous products depends on the composition, but with the assumption of a fixed CE the specific enthalpy is also fixed. Even if the $\mathrm{CE}$ varies, there is no large influence on the EE. With the appropriate enthalpies of reaction $\left(\Delta_{r} H_{C O}^{0}=282,98 \mathrm{~kJ} / \mathrm{mol}, \Delta_{r} H_{H_{2}}^{0}=285,83 \mathrm{~kJ} / \mathrm{mol}\right.$ and $\left.\Delta_{r} H_{C_{2} H_{4}}^{0}=1411,15 \mathrm{~kJ} / \mathrm{mol}\right)$ and the assumption of the oxygen evolution reaction (OER) with liquid water at the anode side 
Equation 7 can be rearranged to

$$
\begin{gathered}
\eta_{E E}=\frac{\eta_{C E, C O} \Delta_{r} H_{C O}^{0}}{E_{\text {cell }} z_{C O} F}+\frac{\eta_{C E, H_{2}} \Delta_{r} H_{H_{2}}^{0}}{E_{\text {cell }} z_{H_{2}} F}+\frac{\eta_{C E, C_{2} H_{4}} \Delta_{r} H_{C_{2} H_{4}}^{0}}{E_{\text {cell }} z_{C_{2} H_{4}} F} \\
\eta_{E E}=\frac{1.46 \mathrm{~V} \eta_{C E, C O}+1.48 V \eta_{C E, H_{2}}+1.21 V \eta_{C E, C_{2} H_{4}}}{E_{\text {cell }}}
\end{gathered}
$$

The slight differences in EE for a silver-based $(\mathrm{Ag})$ electrochemical reduction for different ratios of $\mathrm{CO}: \mathrm{H}_{2}$ become obvious in Equation 9 by comparison of the thermoneutral voltages for $\mathrm{CO}$ - and $\mathrm{H}_{2}$-formation $\left(1.46 \mathrm{~V}\right.$ vs. $1.48 \mathrm{~V}$ ). If other products like $\mathrm{C}_{2} \mathrm{H}_{4}$ are present in the gaseous stream leaving the ecMR the calculation of the EE needs more calculation effort, see Equation 9. But in the case of a Ag-based $\mathrm{CO}_{2}$ reduction the EE can simply be calculated with $\mathrm{E}_{\text {cell }}$. Summarized, a comparison of different cell designs can be done by three indicators: a) $\mathrm{E}_{\text {cell }}$ as a measure for the $\mathrm{EE}, \mathrm{b}$ ) the $\mathrm{CD}$ as a measure for possible production rates and c) the $\mathrm{CE}$ as a measure for the activity towards $\mathrm{CO}_{2}$ reduction compared to side reactions.

\section{Electrode Preparation}

Full metal electrode preparation $\mathrm{Cu}$ foil (thickness $1.0 \mathrm{~mm}$, Sigma Aldrich, 99.999\% metals basis) and Ag foil (thickness $0.1 \mathrm{~mm}$, Sigma Aldrich, 99,998\% metals basis) were used as full metal electrode cathodes. Before electrolysis experiments the electrodes were mechanically polished (subsequent 500, 1000, 2000, 4000 sandpaper) until no discoloration was visible. For the $\mathrm{Cu}$ electrode, subsequent electropolishing in phosphoric acid (85\%, Alfa Aesar) was applied potentiostatically at $-2.1 \mathrm{~V}$ vs. graphite electrode (T-45, Novotec B.V.) (1.5 cm electrolyte gap). Afterwards, both electrodes were rinsed with water to remove remaining impurities. The platinized titanium counter electrode, used for set-ups b) to e), was rinsed with water prior to every experiment.

Gas diffusion electrode (GDE) preparation Silver ( $\mathrm{Ag}$ ) powder (50-60nm, 99.9\%, iolitec) and copper $(\mathrm{Cu})$ powder $(25 \mathrm{~nm}, 99.5 \%$, iolitec) were used as the active catalyst of the cathode GDE with a loading of $5 \mathrm{mg} \mathrm{cm}^{-2}$. The catalyst at the anode was iridium oxide $\left(\mathrm{IrO}_{2}\right)$ (99.99\%, Alfa Aesar) with a loading of $2 \mathrm{mg} \mathrm{cm}^{-2}$. The GDEs were prepared by spraying the catalyst ink on a gas diffusion layer (GDL, Freudenberg, H2315 I2 C6) or directly on the cation exchange membrane (CEM) for the anode. The catalyst ink was prepared as follows: The catalyst was mixed with $2 \mathrm{ml}$ of deionized water $(18.2 \Omega \mathrm{cm}), 2 \mathrm{ml}$ of isopropyl alcohol (Sigma Aldrich, 99.7\%) and $20 \%$-wt. of the amount of catalyst of polymeric binder for Fumion-bonded GDEs and 15\% for PTFE-bonded GDEs. The first polymeric binder was of the same material as the used membrane, a Fumion $141005 \%$-wt. solution. The second one was a PTFE (60 wt\%-solution, Alfa Aesar). After mixing, the catalyst ink was ultrasonically treated for 10 min to obtain a stable suspension. In the case of the $\mathrm{IrO}_{2}$ GDEs, some drops of glycerol were added to adjust the viscosity for which a stable suspension was obtained. The solution was then air-brushed onto the substrate. During this treatment, the substrate was fixed on a heated vacuum table. Vacuum was only switched on for coating membranes to prevent wrinkling of the membrane due to water uptake. The table temperature was kept 
close to $110^{\circ} \mathrm{C}$, slightly above the boiling points of the solvents. This ensured rapid evaporation of the solution and a uniform catalyst layer. Subsequently, the PTFE-bonded electrodes were pressed at 325 bar for 1 min at ambient temperature. Afterwards, the Fumion-bonded GDEs were sintered at $135{ }^{\circ} \mathrm{C}$ for $1 \mathrm{~h}$, which is slightly above the glass transition temperature of the polymer. The PTFE-bonded GDEs were sintered for $1 \mathrm{~h}$ at $340^{\circ} \mathrm{C}$. Finally, the iridium-based GDEs were boiled in $10 \% \mathrm{HCl}$ to remove glycerol. PEM water electrolysis experiments for the $\mathrm{IrO}_{2}$ GDEs yielded a potential of $1.9 \mathrm{Vvs} \mathrm{SHE}$ at $1000 \mathrm{~mA} \mathrm{~cm}^{-2}$ at $70{ }^{\circ} \mathrm{C}$ in a fuel cell like set-up, see Figure 3 set-up a), which is comparable to other works. [21].

Measurement equipment Two gear pumps by Ismatec (MCP-Process, Z-140 HC) were used for the recirculation in set-ups a) and d) to $\mathrm{f}$ ). A flow meter (Endress and Hauser, IP67/NEMA/Type 4X) and two differential pressure gauges (WIKA Alexander Wiegand $\mathrm{SE}$ and Co. KG) were installed at the cathode side to monitor flow characteristics. One differential pressure gauge monitored the pressure loss over the GDE and second one monitored the pressure drop between recirculation inlet and outlet. Self-made heat exchangers enabled control of the process temperature. The gaseous flows were regulated by two mass flow controllers (Bronkhorst). A second $\mathrm{CO}_{2}$ supply at the anode side controlled the $\mathrm{CO}_{2}$ activity in the anolyte and the system pressure. Self-made gas-liquid separators were installed to transfer droplet-free gaseous products to an online gas chromatograph (GC, Thermo Fischer - Trace GC Ultra) coupled with mass spectroscope (MS, Thermo Fischer - ISQ) analysis. A molsieve column (Agilent) was installed for analyzing permanent gases, e.g. $\mathrm{H}_{2}, \mathrm{O}_{2}$ and $\mathrm{CO}$ with argon as carrier gas and a thermal conductivity detector (TCD). On a second parallel channel a Pora Plot Q (Agilent) column was installed to determine product concentrations for light hydrocarbons e.g. $\mathrm{CO}, \mathrm{CH}_{4}, \mathrm{C}_{2} \mathrm{H}_{4}$ and $\mathrm{C}_{2} \mathrm{H}_{6}$ with helium as carrier gas and a TCD or MS as detector. The GC/MS was calibrated before every experiment with a gas of known concentrations. For low concentration detection with the MS a different calibration gas was used as for the TCD. Samples of the products were automatically analyzed every ten minutes. The gas flow leaving the cathode compartment was measured with a Supelco Optiflow 500. The pH value and conductivity of the electrolyte solutions were monitored with a Mettler Toledo - Easy Five Plus and a WTW - inoLAB Cond 7110. Calibration for $\mathrm{pH}$ measurement was performed before every experiments with a three point calibration ( $\mathrm{pH} 1.68, \mathrm{pH} 4, \mathrm{pH} 6.86, \mathrm{pH} 9.18, \mathrm{pH} 12.45)$. 
Table S3: Cathodic and anodic pH evaluation for $\mathrm{CO}_{2}$ reduction for setup b) (discontinuous with blank metal electrodes and divided electrolytes), set-up e) (cathode-continuous divided system using a gas diffusion electrode as cathode and a buffered batch mode anode) and set-up f) (fully continuous divided system using a gas diffusion electrode as cathode and a zero gap anode configuration).

\begin{tabular}{|c|c|c|c|c|}
\hline Applied current $\left[\mathrm{mA} \mathrm{cm}^{-2}\right]$ & $\mathrm{pH}_{\text {cathode, } \mathrm{Ag}}$ & $\mathrm{pH}_{\text {anode, } \mathrm{Ag}}$ & $\mathrm{pH}_{\text {cathode, } \mathrm{Cu}}$ & $\mathrm{pH}_{\text {anode, }} \mathrm{Cr}$ \\
\hline \multicolumn{5}{|l|}{ set-up b) } \\
\hline-10 & 7.01 & 2.11 & 6.88 & 2.10 \\
\hline-20 & 7.23 & 1.92 & 7.23 & 1.84 \\
\hline-30 & 7.49 & 1.71 & 7.48 & 1.59 \\
\hline-50 & 7.66 & 1.60 & 7.62 & 1.36 \\
\hline-70 & 7.72 & 1.42 & 7.69 & 1.30 \\
\hline-100 & 7.82 & 1.34 & 7.89 & 1.33 \\
\hline \multicolumn{5}{|l|}{ set-up e) } \\
\hline-10 & 6.08 & 2.35 & 5.72 & 2.16 \\
\hline-20 & 6.46 & 1.81 & 6.21 & 1.65 \\
\hline-30 & 6.77 & 1.53 & 6.31 & 1.47 \\
\hline-50 & 6.92 & 1.44 & 6.42 & 1.34 \\
\hline-70 & 6.92 & 1.41 & 6.45 & 1.22 \\
\hline-100 & 6.80 & 1.34 & 6.57 & 1.14 \\
\hline \multicolumn{5}{|l|}{ set-up f) } \\
\hline-10 & 5.53 & 3.47 & 5.41 & 3.31 \\
\hline-20 & 5.93 & 3.01 & 5.81 & 2.98 \\
\hline-30 & 6.32 & 2.63 & 6.18 & 2.57 \\
\hline-50 & 6.61 & 2.46 & 6.41 & 2.28 \\
\hline-70 & 6.87 & 2.25 & 6.67 & 2.05 \\
\hline-100 & 7.18 & 2.02 & 6.91 & 1.81 \\
\hline
\end{tabular}

